\title{
Cospeech Gestures Are a Window Into the Effects of Parkinson's Disease on Action Representations
}

\author{
Stacey Humphries ${ }^{1,2}$, Judith Holler ${ }^{3,4}$, Trevor Crawford $^{5}$, and Ellen Poliakoff ${ }^{1}$ \\ ${ }^{1}$ Division of Neuroscience and Experimental Psychology, University of Manchester \\ ${ }^{2}$ Department of Neurology, University of Pennsylvania \\ ${ }^{3}$ Donders Institute for Brain Cognition and Behaviour, Radboud University \\ ${ }^{4}$ Communication in Social Interaction Group, Max Planck Institute for Psycholinguistics \\ ${ }^{5}$ Department of Psychology, Lancaster University
}

\begin{abstract}
Parkinson's disease impairs motor function and cognition, which together affect language and communication. Cospeech gestures are a form of language-related actions that provide imagistic depictions of the speech content they accompany. Gestures rely on visual and motor imagery, but it is unknown whether gesture representations require the involvement of intact neural sensory and motor systems. We tested this hypothesis with a fine-grained analysis of cospeech action gestures in Parkinson's disease. Thirty-seven people with Parkinson's disease and 33 controls described 2 scenes featuring actions which varied in their inherent degree of bodily motion. In addition to the perspective of action gestures (gestural viewpoint/first- vs. third-person perspective), we analyzed how Parkinson's patients represent manner (how something/someone moves) and path information (where something/someone moves to) in gesture, depending on the degree of bodily motion involved in the action depicted. We replicated an earlier finding that people with Parkinson's disease are less likely to gesture about actions from a first-person perspective - preferring instead to depict actions gesturally from a third-person perspective — and show that this effect is modulated by the degree of bodily motion in the actions being depicted. When describing high-motion actions, the Parkinson's group were specifically impaired in depicting manner information in gesture and their use of third-person path-only gestures was significantly increased. Gestures about low-motion actions were relatively spared. These results inform our understanding of the neural and cognitive basis of gesture production by providing neuropsychological evidence that action gesture production relies on intact motor network function.
\end{abstract}

Keywords: gesture, imagery, Parkinson's disease, action, simulation

Supplemental materials: https://doi.org/10.1037/xge0001002.supp

Cospeech gestures are the spontaneous movements of the hands and arms that people produce when they talk, and thus link two core domains of cognition: language and action. While much of the early research on gestures focused on their relationship to speech

This article was published Online First February 1, 2021.

Stacey Humphries (D) https://orcid.org/0000-0001-9681-660X

Open data and code available at: https://osf.io/dmry9/. Judith Holler and Ellen Poliakoff are joint senior authors. Preliminary results from this study were presented in a poster presentation at the Cognitive Neuroscience Society meeting in 2017, San Francisco, California. Stacey Humphries was supported by a PhD Studentship from Parkinson's United Kingdom (H1104). The authors would like to acknowledge the contributions of Matthew Sullivan, who helped to guide this research from the perspective of a person with Parkinson's disease. The authors also thank Maia Birch, William Coath, Natalia Schwartz, and Ece Bayram for their assistance in transcription, as well as Jade Pickering for her assistance in recoding gestures for the purpose of establishing reliability.

Correspondence concerning this article should be addressed to Stacey Humphries, Department of Neurology, University of Pennsylvania, Goddard Labs, 3710 Hamilton Walk, Philadelphia, PA 19104, United States. Email: HStace@pennmedicine.upenn.edu
(Kendon, 1997; McNeill, 1985, 1992; Willems \& Hagoort, 2007), later work has also examined the relationship between gesture and action. Numerous theories such as the Interface hypothesis (Kita \& Özyürek, 2003), the Gesture as Simulated Action (GSA) framework (Hostetter \& Alibali, 2008; Hostetter \& Alibali, 2019), the Sketch model (de Ruiter, 2000) and the Gesture-forConceptualization hypothesis (Kita et al., 2017) propose that gestures arise from and are shaped by mental representations, which are variously referred to as imagery or simulations. While there is substantial evidence that imagery (or simulation) indeed influences gesture production, it remains unknown whether mentally constructing a perceptual or motor experience for gesture production requires the involvement of intact neural perceptual and motor systems. In this study, we address this question by examining the gestures produced by patients with a neurodegenerative disease affecting the motor system.

Imagery has been described as internally generated representations that are of the same type as those created during perception and action, except that nothing is actually being perceived (Kosslyn et al., 2006). Under this view, a mental image should rely on perceptual, sensory, and motor systems in the brain. An alternative 
view is that mental images are not "images" per se, but are language-like propositional representations (Pylyshyn, 1973). In this alternative view, imagery is based on abstract, amodal symbols, and is thus not dependent on sensorimotor brain states. Simulation is defined as the recreation of perceptual or motor states in the absence of external input, which activates similar perceptual and motor systems to those which would be activated during actual perception or movement (Jeannerod, 2001; Jeannerod \& Frak, 1999). There are clear theoretical parallels between simulation and at least some formulations of imagery, and researchers differ in the extent to which they believe these two terms describe the same process. In this paper, we do not aim to tease apart or contrast these different notions. We use the term imagery to describe mental representations of perceptual and sensorimotor concepts, and we test the hypothesis that the motor system functionally contributes to motor imagery by observing the gestures people produce when they talk about actions.

If gestures are the product of imagery, mental images of actions or bodily movements (motor imagery hereon, see Jeannerod, 1994) appear to exert a particularly strong influence over several aspects of gesture production, and there is clear empirical evidence for this. First, people gesture more when they talk about actions and action-relevant objects, compared to other topics. For example, speakers produced more representational gestures when describing high-affordance objects compared to low-affordance objects, such as a whisk compared to a plant (Chu \& Kita, 2016; Hostetter, 2014; Masson-Carro et al., 2016; Pine et al., 2010). Similarly, when describing topics that trigger motor imagery (e.g., how to change the wheel of a car), visual imagery (e.g., a favorite painting), and more abstract topics (e.g., your opinion on a single currency in Europe), speakers gestured the most about motor topics and the least about abstract topics (Feyereisen \& Havard, 1999). Second, object affordances influence the form of the representations depicted by gesture. People produced more gestures that imitated an action or mimicked gripping an object when describing high-affordance objects, and more molding and tracing gestures that highlighted shape when describing low-affordance objects (Masson-Carro et al., 2016). Even when solving problems silently, people produced more "cothought" gestures when they mentally rotated high-affordance mugs (with smooth surfaces) compared to low-affordance mugs (with spiky surfaces; Chu \& Kita, 2016). Additionally, different aspects of an event structure affect the likelihood with which speakers adopt a first-person perspective (or "character viewpoint") or a third-person perspective (or "observer viewpoint") in their gestures (Parrill, 2010). In a cartoon narration study, events that involved a character's hands, torso, or face evoked exclusively character viewpoint (CVPT) gestures, while events that involved long trajectories, which could not be simulated on a human scale, evoked exclusively observer viewpoint (OVPT) gestures (Parrill, 2010). CVPT gestures may thus be based on motor imagery, where the speaker imagines themselves actually producing movements, while OVPT gestures may be based more on visual imagery, where the speaker imagines how the event looked from the outside. Finally, individual differences in cognitive ability and action experience affect the way people gesture about actions. People with high spatial ability gesture more about dynamic information, while speakers with low spatial ability gesture more about static information (Göksun,
Goldin-Meadow, et al., 2013). Additionally, experience with physically manipulating objects alters the way that speakers subsequently gesture (Cook \& Tanenhaus, 2009; Hostetter \& Alibali, 2010).

While there are clear differences in gestures based on motor and visual imagery, the line between these two types of imagery can become conceptually blurred, particularly when visual imagery is about a motor event. Research on motor imagery has distinguished between kinesthetic and visual forms of motor imagery that have different neural substrates. Kinesthetic motor imagery involves imagining the felt sensations of producing motor acts from a first-person perspective, while visual motor imagery involves imagining seeing oneself (or someone else) produce movements from a third-person perspective. Only kinesthetic motor imagery is associated with activity in primary motor areas (Neuper et al., 2005) and the modulation of corticomotor excitability (Stinear et al., 2006; Voisin et al., 2011), while visual cortex activity was negatively correlated with the vividness of kinesthetic imagery (Mizuguchi et al., 2016). As outlined above, since CVPT gestures are direct imitations of actions from a first-person perspective, we expect that they rely primarily on kinesthetic motor imagery instantiated in motor areas of the brain. In contrast, since OVPT gestures, even when they are about actions, are third-person representations of how an action looks from the outside, without containing corresponding kinesthetic information, we expect that they rely primarily on visual motor imagery instantiated in visual areas. We use motor imagery to refer specifically to kinesthetic motor imagery, and visual imagery to refer to both motor and nonmotor visual imagery without a kinesthetic component.

This body of evidence suggests that visual and motor imagery indeed contribute to gesture production, but whether this imagery requires the involvement of intact visual and motor brain systems is unknown. As proposed by Pylyshyn (1973), it is possible that speakers instead represent information using a symbolic, verbal, or propositional code. Indeed, as well as being a form of action, gestures are also semantic in nature and are closely connected to the content of speech. As such, their underlying cognitive representations may be abstracted away from specific sensory-motor modalities. Some theories of language processing distinguish between two interacting systems: a modal simulation system and a distributed linguistic system based on knowledge of statistical co-occurrences of words in natural language (Barsalou et al., 2008; Lynott \& Connell, 2010). Thus, an alternative hypothesis would be that speakers are likely to gesture about actions when viewing high-affordance objects, because action words have a high degree of co-occurrence with object words in natural language (and the more so the stronger the motor affordances of an object), and viewing objects causes these closely connected action words or symbols to be automatically activated through a distributed linguistic system.

Many previous gesture studies have conducted elegant behavioral analyses of healthy participants' gestures, but these cannot speak to whether the imagery, which gestures are assumed to be based on, necessarily requires the involvement of modal neural systems. Studies of lesion or neurodegenerative patients can be a powerful way to examine the effects of damaged neural structures on gesture production, while maintaining the naturalistic dyadic paradigms employed in gesture research. So far, relatively few studies have examined the production of gestures depicting actions 
or spatial events in lesion patients with impairedlanguage abilities. A patient with severe anomia who was unable to retrieve words to describe motion events was nevertheless able to produce detailed iconic gestural depictions of those events (Kemmerer et al., 2007). Similarly, patients who were impaired at naming spatial relations produced more spatial gestures (Göksun, Lehet, et al., 2013), which may reflect a compensatory mechanism (Göksun et al., 2015). However, very few patient studies have tested the effects of an impaired motor system rather than an impaired language system. If motor imagery necessarily depends on the brain's motor system, patients with damaged motor systems should be impaired in the production of gestures that depict actions. To test the causal role of intact motor network function in representing actions in cospeech gestures, we examined the gestures produced by people with Parkinson's disease.

Parkinson's disease is a neurodegenerative movement disorder characterized by bradykinesia, rigidity, tremor, and postural instability, which is caused primarily by the degeneration of dopaminergic neurons in the substantia nigra pars compacta, which project to the striatum (i.e., the caudate nucleus and putamen) in the basal ganglia. The basal ganglia receive input from multiple, widespread cortical areas, and integrate these inputs to modulate the output of the motor cortex via the thalamus (Alexander \& Crutcher, 1990; Groenewegen, 2003; Hoover \& Strick, 1993). Functional activation of motor cortical areas is disturbed in Parkinson's disease, with hypoactivation and hyperactivation of motor regions (Buhmann et al., 2003; Haslinger et al., 2001; Pasquereau et al., 2016; Sabatini et al., 2000; Wu \& Hallett, 2005; Yu et al., 2007) as well as altered connectivity within and between nodes of the motor network (Baudrexel et al., 2011; Wu et al., 2011).

In addition to impairing overt movement production, Parkinson's disease has been shown to affect the cognitive representation of action information in domains such as language and mental imagery (Poliakoff, 2013). Language studies have found that Parkinson's disease patients are specifically impaired in processing verbs, or language with action content. Verbs and action concepts are argued to be at least partially instantiated in primary motor and premotor cortex (see Kemmerer, 2015, for a review). For example, people with Parkinson's disease demonstrated a deficit in generating lists of verbs in action fluency tasks, compared to other phonetic or semantic fluency tasks (Péran et al., 2009; Piatt et al., 1999; Signorini \& Volpato, 2006). In a study comparing action fluency in Parkinson's patients on-off dopamine medication, it was found that patients off-medication exhibited a verb-specific fluency deficit, producing significantly fewer verbs while fluency for other semantic categories remained unaffected. Restoring dopaminergic medication ameliorated this deficit (Herrera, Cuetos, et al., 2012). Naming actions is also impaired in Parkinson's disease (Cotelli et al., 2007), and this effect is more pronounced for actions associated with a high degree of bodily movement (Bocanegra et al., 2017; Herrera, Rodríguez-Ferreiro, et al., 2012; Humphries et al., 2016), and for patients off-medication relative to on (Herrera \& Cuetos, 2012). In addition, patients are slower or less accurate to make lexical and semantic decisions about action words compared to nonaction words (Bocanegra et al., 2015; Boulenger et al., 2008; Fernandino et al., 2013).

These action language processing impairments may be at least partly explained by changes in motor imagery in Parkinson's disease, which has been investigated using mental rotation tasks.
In healthy adults, the mental rotation of objects engages posterior parietal cortices, particularly in the right hemisphere (Amick et al., 2006; Carpenter et al., 1999; Corballis, 1997; Harris et al., 2000; Podzebenko et al., 2002), and invokes object-centered transformations: objects are mentally rotated in space regardless of the viewer's own position. In contrast, the mental rotation of hands elicits activation in left primary motor, premotor, and supplementary motor frontal areas (Kosslyn et al., 1998), and instead involves viewer-centered transformations, where viewers mentally manipulate a representation of their own body with respect to the target (Cronin-Golomb \& Amick, 2001; Kosslyn et al., 1998; Ogden, 1990). Hand rotation performance is impaired by applying transcranial magnetic stimulation over the hand region of the left primary motor cortex, (Ganis et al., 2000), leading some to suggest that people perform the task by mentally simulating hand movements. Hand rotation also seems to be affected in Parkinson's disease. People with Parkinson's disease performed worse when they mentally rotated hands matching their own more affected hand, and this motor imagery asymmetry was correlated with actual motor asymmetry (Dominey et al., 1995). Similarly, presentation of the hand to the visual field corresponding to the patient's side of onset impaired rotation performance (Amick et al., 2006). Parkinson's disease patients were also more impaired when mentally rotating their most affected hand in a biomechanically challenging direction (Helmich et al., 2007). An fMRI study found that patients engaged the same posterior parietal and premotor regions activated by healthy people during mental hand rotation, but there was additional activation in extrastriate body area (EBA) and occipito-parietal cortex, particularly when viewing images corresponding to their more affected hand (Helmich et al., 2007). The EBA is involved in allocentric visual processing of human body parts (Chan et al., 2004; Urgesi et al., 2004). When the EBA was inhibited using continuous theta burst stimulation, hand rotation was affected in Parkinson's disease but not in control subjects, suggesting that this region was compensating for a function normally performed by the dorsal premotor cortex (van $\mathrm{Nu}$ enen et al., 2012).

This compensatory activity in EBA may indicate that motor imagery in Parkinson's disease is based on allocentric, visual features of movements rather than imagery of movement production from a first-person perspective. Critically, if Parkinson's patients do indeed rely on visual information to compensate for a reduced ability to imagine movement production, theories proposing that gestures are primarily based on motor imagery (or action simulation) would predict that Parkinson's patients would gesture differently to healthy speakers.

What do we know so far about how gesturing changes in Parkinson's disease? Most studies reporting changes to gesturing in Parkinson's disease have in fact been studies of ideomotor apraxia. This literature notes "awkward and clumsy" gestures, and spatial errors in gesturing in Parkinson's disease (Zadikoff \& Lang, 2005). However, the gestures referred to are pantomimes (i.e., gestures in the absence of language) rather than cospeech gestures per se. True cospeech gestures are different from pantomimed actions in several ways. First, cospeech gestures are produced spontaneously by the speaker as part of a communicative act; they are thus connected to a communicative intention rather than produced on request. Second, cospeech gestures occur overwhelmingly in the presence of speech (McNeill, 1985), whereas 
pantomimes produced during apraxia testing are done so in the absence of speech. Furthermore, studies have provided examples of apraxic patients who show impairment in the ability to pantomime action, whereas their cospeech gestures remain relatively unaffected (Bartolo et al., 2003; Dumont et al., 1999; Rapcsak et al., 1993).

A handful of studies have begun to investigate cospeech gestures in Parkinson's disease. Cleary et al. (2011) found that people with Parkinson's disease gestured just as often as controls. However, Parkinson's patients tended to produce less precise gestures than controls when depicting actions that they themselves had previously performed, suggesting that the patients were less able to simulate the previously performed action. Klooster et al. (2015) also found that Parkinson's disease patients produced gestures with reduced curvature compared to controls when they described their own previous curved hand movements. A later study expanded on these findings by examining Parkinson's patients' gestures as they described a broad range of actions (Humphries et al., 2016). It was again found that the rate of gesture production is not affected in mild-moderate Parkinson's disease. However, Parkinson's patients demonstrated a change in the perspective from which they produce action gestures. As described earlier, action gestures can be produced from a first-person perspective, as though pretending to perform the action (CVPT gestures), or from a third-person perspective by depicting allocentric visual features of the action (OVPT gestures). Parkinson's disease patients in Humphries et al. (2016) produced significantly more of their gestures from an OVPT (e.g., tracing the path of a skier down a slope) while controls gestured overwhelmingly from a CVPT (e.g., moving closed fists at the sides of the body, as though holding ski poles). The fact that Parkinson's patients tended to gesture more about visual features is consistent with findings from the mental rotation literature discussed earlier; namely that Parkinson's patients recruited the EBA, implicated in processing allocentric views of body parts, as a way of compensating for some of the neurocognitive processes underpinning motor imagery in healthy people.

Thus, converging lines of evidence demonstrating impairments to action language processing, motor imagery, and action gesture production in Parkinson's disease point to difficulties in conceptualizing, representing and simulating actions in the brains of these patients (Poliakoff, 2013). We propose that Parkinson's disease leads to a failure to fully represent egocentric, kinesthetic features of actions in premotor cortices and a compensatory shift toward representing the allocentric, visual features of actions, by recruiting posterior parietal and occipital regions, including EBA. This hypothesis accounts for the preference for gesturing about actions from a third-person perspective in Parkinson's disease.

To our knowledge, apart from Humphries et al. (2016), no other study has examined gesture viewpoint in any other neuropsychological or lesion patient groups as a means of investigating how disruptions to motor networks affect action depictions in gesture. To fully characterize how disrupted motor networks alter the way people gesture, a comprehensive analysis of action gesture production in Parkinson's disease is required. Such an analysis should identify which features of gestural action depictions are vulnerable to disruption (in addition to gesture viewpoint), and probe the circumstances under which action gesture production might be modulated. We describe here a study conducted in pursuit of these aims.

We have argued that gesture viewpoint is a useful way of accessing features of the representation underlying the gesture, but other features of action events can also be depicted in gesture. An action event consists of several components, two of which are the manner and the path of motion of objects or persons in the event (Talmy, 1985). The manner of a movement refers to the relationship of intrinsic moving body parts in relation to each other, or how the action is performed (Chatterjee, 2008). In English, the manner of a movement is expressed by the main verb of a sentence (e.g., running). In contrast, the path of a movement refers to the trajectory of a moving figure in relation to the background and is expressed in English by prepositional phrases (e.g., across). An action gesture can depict manner alone, path alone, or manner and path combined in a single gesture (Kita \& Özyürek, 2003). Most manner and path gesture studies have concentrated on comparing gestural action depictions in typologically different languages and second-language learners. These comparisons are not of direct relevance here, but it is worth mentioning that English speakers typically represent manner and path together in gesture as one unit (Kita \& Özyürek, 2003; Özyürek et al., 2005, 2008; Özyürek \& Kita, 1999).

Manner and path motion components are processed by different networks in the brain. Attending to manner activates relatively ventral areas (bilateral posterior inferior/middle temporal cortex) while attending to path activates dorsal areas of regions sensitive to motion (bilateral posterior parietal and frontal areas; Wu et al., 2008). Comprehending verbs (manner) is associated with activation in premotor and primary motor areas (for reviews see Pulvermüller, 2005, 2013) and the posterior middle temporal gyrus, while lesions in caudate impair naming manners of motion (Göksun et al., 2015). Comprehending and producing prepositions (path) involves the left posterior inferior parietal and prefrontal cortices (Amorapanth et al., 2010; Baciu et al., 1999; Göksun et al., 2015; Noordzij et al., 2008). As outlined above, Parkinson's patients exhibit disturbed functional activation of motor cortical regions and are specifically impaired in the comprehension of verbs that denote manner information. On the other hand, we are not aware of any reports that Parkinson's disease impairs the production or comprehension of prepositions; while gestural depictions of manner information may be particularly vulnerable in Parkinson's disease, path gestures may thus be preserved.

\section{The Present Study: Predictions}

Based on the hypothesis that motor imagery is affected by Parkinson's disease, we predicted that people with Parkinson's would be impaired in the production of both CVPT and manner gestures. As described earlier, Parkinson's patients appear to have a specific impairment in imagining actions from a first-person perspective. If gestures arise from imagery, this first-person motor imagery impairment should lead to a corresponding reduction in CVPT gestures, as these depict actions from a first-person perspective. In addition, a specific action-language or verb impairment in Parkinson's disease has been identified in previous research. Because manner information is expressed by verbs (in English), we expected to see an impairment in the ability to depict manner information in gesture in Parkinson's disease. It is worth 
noting here that there is some correspondence between CVPT gestures and manner information in gesture. CVPT gestures that depict actions by their very nature depict manner information. The speaker's hands (or whole body) directly map on to the hands (or whole body) of the character being described and show an "acting out" (i.e., manner) of the action. CVPT gestures need not necessarily depict path information, though they may (e.g., depicting someone climbing up a ladder). In contrast, OVPT gestures depicting actions may depict manner (e.g., wiggling two fingers to show "running"), or path (e.g., tracing a line with an index finger), or both. Critically, when manner information is present in OVPT gestures, it is depicted from a third-person rather than a firstperson perspective. Path information may be more likely in OVPT gestures, as they are often used to trace the path of a figure in space. ${ }^{1}$ Thus, to summarize, because Parkinson's disease patients demonstrate impairments in both representing verbs, and firstperson motor imagery, we predicted that they would also be impaired in the production of CVPT and manner gestures. In contrast, we predicted that Parkinson's disease patients would not be impaired in the production of OVPT or path gestures because they do not require a simulation of the first-person perspective and only rarely involve kinesthetic features of a movement.

A further aim of the present study was to explore how the use of viewpoint, manner, and path gestures in Parkinson's disease might be modulated by features of the event being described. We have previously proposed that the reduction in usage of CVPT gestures in Parkinson's disease reflects impaired motor imagery (Humphries et al., 2016). Previous work on various forms of action representation in Parkinson's disease suggests that the nature of the movement to be simulated is critical (Poliakoff, 2013). Movements which are fast (Castiello et al., 2009), difficult to produce (Helmich et al., 2007), or involve a greater degree of bodily motion (Herrera, Rodríguez-Ferreiro, et al., 2012) appear to be particularly vulnerable to representational impairments in Parkinson's disease. Parkinson's disease patients may therefore be less able to imagine movements that they themselves are less able to perform, such as those involving a greater degree of strength, balance, agility, and bodily motion (high-motion actions, hereon), which could affect the way they gesture about those actions. If motor imagery for high-motion actions is particularly affected in Parkinson's disease, imagery for these actions may be especially likely to be "visual" (i.e., based on third-person visual perspectives of actions) and may lack some of the motor features that healthy speakers include in their imagery (cf. Helmich et al., 2007). Thus, Parkinson's disease patients should correspondingly produce fewer CVPT and manner gestures, and more OVPT and path gestures, when they describe high-motion actions, while imagery for low-motion actions, which are still within a patient's motor repertoire (see Castiello et al., 2009), may be unaffected. We therefore aimed to assess how differing degrees of motor content affected manner and path action gesture depictions as well as the viewpoint from which the gestures were produced.

To summarize, this study was designed to test the hypothesis that the imagery underlying gesture production relies on representations from intact sensorimotor brain systems, by investigating how actions are depicted in the gestures of patients with impaired motor systems. The predictions derived from this hypothesis are (a) people with Parkinson's disease would produce fewer gestures depicting the manner of motion of an action, (b) people with
Parkinson's disease would produce fewer action gestures from a first-person perspective (CVPT), (c) people with Parkinson's disease would compensate for a reduced motor imagery ability by producing more gestures from a third-person perspective (OVPT), depicting only visual features such as path information, and (d) that these effects would be more pronounced when people with Parkinson's disease described actions involving a high degree of bodily motion.

\section{Method}

\section{Participants}

Thirty-seven people with mild-to-moderate Parkinson's disease and 33 neurotypical age-matched controls participated in this study, which was approved by the local National Health Service research ethics committee (reference 11/NW/0143). The groups did not differ significantly in age (Parkinson's group $M=65$, $S D=7.31$, Control group $M=66, S D=6.02$ ) or years of education (Parkinson's group $M=14.78, S D=3.75$, Control $M=$ $15.91, S D=3.02$ ). Participants were excluded if they had ever had a stroke, if they had any other neurological conditions other than Parkinson's, if they had any psychiatric illnesses, if they had undergone deep brain stimulation, if they had ever sustained a serious head injury, if English was not their native language, or if they had a sight or hearing impairment rendering them unable to see and/or hear video clips on a computer screen or understand verbal instructions. Participants were also screened for dementia using the Addenbrookes Cognitive Examination-ACE-III (Hsieh et al., 2013) using a cut-off score of 82 out of 100 (Mioshi et al., 2006). Thus, all patients included in the study were cognitively normal $(M=93.19, S D=4.62)$. Approximately 10 participants in the Parkinson's disease group participated in a previous gesture study by the same authors (Humphries et al., 2016). The data reported here were collected 2 years after data collection for this previous study. In both studies, participants were informed that their communication skills were being tested, but no explicit reference was made to gesture production.

Parkinson's patients were recruited at Hoehn and Yahr Stage III or less (Hoehn \& Yahr, 1967). There were three patients at Stage 1, 31 at Stage 2, and three at Stage 3. The Part 3: Motor examination subsection of the Unified Parkinson's Disease Rating Scale (UPDRS) was administered on the day of testing to evaluate the severity of the patients' motor symptoms $(M=36.24, S D=$ 11.78). The patients' average age of onset was $58.19(S D=8.76)$, ranging from 39 to 75 , and their average disease duration was 6.56 years $(S D=4.34)$, ranging from 1 to 20 . All patients were taking dopaminergic medication and were tested on their usual regimen at a time of day selected by themselves to maximize a stable "on" period. A daily levodopa equivalent dose was calculated for each participant $(M=681.26, S D=339.07$; Tomlinson et al., 2010).

\section{Cartoon Narration Task}

To investigate whether the degree of bodily motion in the actions being described (high or low) influenced the extent to

\footnotetext{
${ }^{1}$ Note that gestures fusing different viewpoints, such as Body As Reference Point (BARP) gestures (Holler \& Beattie, 2002) and Dual Viewpoint (DVPT; Parrill, 2009) did not occur in the present dataset.
} 
which action information (viewpoint, manner, and path) was encoded in gesture in people with and without Parkinson's disease, we selected scenes featuring high- and low-motion actions from a cartoon stimulus; the Sylvester and Tweety "Canary Row" cartoon. We edited the cartoon to shorten it and reduce the resulting memory load for participants. The edited version included a scene featuring high-motion actions and a scene featuring low-motion actions (see the Motion Scene Coding section for detail). Participants viewed the cartoon twice, and then were asked to retell the events they had just seen in as much detail as possible to a confederate addressee. Participants were told that the addressee would later be asked questions about the content of the cartoon, based on what they had learned from the participant's retelling, and that the addressee's performance would be considered as a measure of their joint achievement on the task. Participants were not informed until the end of the session that the study was investigating gesture production. Addressees were instructed not to interfere with the participants' descriptions (e.g., by interrupting or asking questions), but to indicate that they were paying attention to the speaker and were engaged with their description through backchannel feedback.

\section{Motion Scene Coding}

Two scenes from the stimulus cartoon were assigned as predominantly featuring low- and high-motion actions. The lowmotion scene contained actions such as listening, watching, talking, and holding, which require a relatively low degree of bodily motion to achieve. The high-motion scene contained actions such as climbing, running, and jumping, which involve a high degree of bodily motion (further information in the online supplemental materials). Our classification of low- and high-motion actions is in line with previous action naming studies that classified similar actions based on normative ratings of their motion content (Bocanegra et al., 2017; Herrera, Rodríguez-Ferreiro, et al., 2012). A large-scale norming study of the motor content of verbs validates our classification (San Miguel Abella \& González-Nosti, 2020). Verbs featured in our low-motion scene were rated lower for motor content on a 7-point scale (e.g., listening $=1.52$, watching $=1.91$, talking $=3.3$, holding $=2.31$ ) than verbs featured in our highmotion scene (e.g., climbing $=4.63$, running $=6.15$, jumping $=$ 5.65). The low-motion scene featured Sylvester hiding in a mailroom and listening in on a telephone conversation. In disguise, he creeps up to an apartment room and steals a suitcase and a birdcage. The high-motion scene showed Sylvester climbing up a telegraph pole and tightrope walking across tram wires. He is chased by a tram and starts to run and jump away frantically to avoid being electrocuted. A full list of the actions present in each scene is included in Table 1. Manner and path were salient to different degrees in different actions. Actions where manner was salient, actions where path was salient, and actions where both manner and path were salient were present in both scenes. As shown in Table 1, while the low-motion and high-motion scenes largely comprised corresponding low- and high-motion actions, a small number of low-motion actions (e.g., talking, pointing) were common to both scenes.
Table 1

Lists of the Actions Present in Each Scene

\begin{tabular}{|c|c|}
\hline Actions in low-motion scene & $\begin{array}{l}\text { Actions in high-motion } \\
\text { scene }\end{array}$ \\
\hline Picking up [telephone] & Pacing (back and forth) \\
\hline Nodding & Bounding (across street) \\
\hline Talking & Looking up \\
\hline Hiding [hands touching face] & Climbing (up a pole) \\
\hline Listening [hand behind ear] & Tightrope walking (across) \\
\hline Knocking [door] & $\begin{array}{l}\text { Balancing [arms out to the } \\
\text { sides] }\end{array}$ \\
\hline Pointing & Running (across) \\
\hline Opening [door] & Jumping \\
\hline Walking (into room) & Steering [wheel] \\
\hline Holding [birdcage] & Talking \\
\hline Creeping (along hallway and down stairs) & Pointing \\
\hline Throwing [suitcase] (down hallway) & Pulling [bell] \\
\hline Rubbing together [hands] & \\
\hline
\end{tabular}

Note. Salient path information is included in parentheses. Additional salient information about manner or objects being used is including in brackets.

\section{Transcription}

The recorded cartoon narrations were transcribed by three native English speakers. The videos were converted to audio-only files so that the transcribers remained blind to the disease status of the participant. Narrations were transcribed verbatim including stutters, repetitions, false starts and filled pauses.

\section{Gesture Coding}

Gesture coding was conducted in the ELAN annotation software (https://tla.mpi.nl/tools/tla-tools/elan/; Sloetjes \& Wittenburg, 2008). Gestures are usually triphasic, except where they occur in succession, consisting of a preparation movement, stroke, and retraction (McNeill, 1992). Each new stroke (the main movement of the gesture that carries its meaning) was counted as a gesture. Where multiple gestures occurred in quick succession without the hands returning to rest, they were separated according to the following criteria (not all of these need apply): (a) a new, clear preparation phase, (b) a change in hand form, and (c) if the same hand form is retained, there is a noticeable break or change in movement from one gesture to the next one. Movements not involved in speaking or communicating such as self-grooms were excluded. A second coder independently identified all gestures occurring within $25 \%$ of the low-motion and $25 \%$ of the high-motion descriptions from each participant. This resulted in 91.61\% agreement for gesture identification.

Each identified gesture was first categorized according to whether it was representational (depicted any kind of semantic information) or nonrepresentational (gestures with pragmatic functions such as adding emphasis). The second coder recoded $25 \%$ of the gestures from each participant for type (534 gestures), resulting in $88.49 \%$ agreement (Cohen's $\kappa=.71$ ). Representational gestures were then further classified according to whether or not they represented action information. Action information could include the manner of an action, the path of a figure, or both (examples described below). Action gestures could also be produced either from a CVPT, or from an OVPT. If only an object was depicted (e.g., showing the shape of a bird cage with the hands) this was not 
counted as an action gesture. Only gestures that specifically represented actions or movements were included. The second coder recoded $25 \%$ of each participant's representational gestures (385 gestures) for action information, resulting in a percentage agreement of $88.57 \%$ and Cohen's Kappa .77 .

Action gestures were further coded as to whether or not they contained manner information (the way a figure moves intrinsically regardless of its trajectory), path information (the trajectory of a figure with respect to its background), and from which viewpoint (character-CVPT, observer-OVPT) they occurred.

CVPT gestures were coded when the speaker's hands directly mapped onto the hands of the character being described. CVPT gesture examples from the low-motion scene included (a) making a closed fist with the hand while flexing and extending the wrist to imitate knocking on a door (manner), and (b) making a loose fist with the hand and lifting it up to the ear to imitate answering the telephone (manner). CVPT gesture examples from the high-motion scene include (a) making claw shapes with both hands and moving them one above the other in an upward trajectory to imitate climbing upward (manner and path), and (b) extending both arms out to the side with palms down, imitating the balancing action involved in tightrope walking (manner).

OVPT gestures were coded when the speaker's hand(s) depicted an entire figure. Examples from the low-motion scene included (a) using the index finger to draw a straight line forward, indicating Sylvester's path into the room (path only), and (b) with the whole hand pointing downward and moving horizontally, using the index and middle finger to represent Sylvester's legs and moving them slowly back and forth to describe "creeping" (manner and path). OVPT gesture examples from the high-motion scene include (a) using the index finger to trace a straight line upward, indicating Sylvester's ascent up the telegraph pole (path only), and (b) tracing quick semicircles with the finger while moving the hand horizontally, indicating Sylvester bouncing along the telegraph wires (manner and path).

The second coder recoded $25 \%$ of each participant's action gestures (206 gestures) for manner, path, and viewpoint. For manner, there was a percentage agreement of $88.83 \%$ and a Cohen's Kappa of .76. For path, there was a percentage agreement of $91.75 \%$ and a Cohen's Kappa of .83. For viewpoint, the percentage agreement was $92.72 \%$ with a Cohen's Kappa of .85 .

\section{Data Analysis}

To account for slower speaking rates and reduced verbal output in Parkinson's disease, all gesture production measures were converted from raw numbers into gestures per 100 words. We calculated overall gestures per 100 words, gestures depicting actions per 100 words, and the action subcategories of manner, path, CVPT, and OVPT gestures per 100 words. Note that in our previous article (Humphries et al., 2016), we analyzed the proportion of action gestures produced from a CVPT. In this dataset, there were some instances were a participant produced only one gesture of a certain type. We were concerned that entering this data point as "100\%" gave a misleading view of how frequently certain gestures were produced. We therefore opted to analyze the rate of production rather than proportions in this study. However, we report the analyses on the same data expressed as proportions in the online supplementary materials point 1 to enable comparison with our previous study.

To investigate the effects of motion content on gesture production, the narrations were split according to the words and gestures produced when describing the low and high-motion scenes. During their narrations, some participants failed to describe one of the scenes, resulting in missing data for those scenes. Additionally, even when participants described a scene, they may not have produced any gestures. For the overall gesture rate analysis, participants who did not gesture were included with a gesture rate of zero but were excluded from further analysis. Participants who gestured at least once were included in the action gesture rate analysis. Participants who produced no action gestures were excluded from further analysis of the action gesture subcategories (manner, path, etc.). People who produced action gestures were included in all the subsequent analyses breaking down these action gestures into manner, path, CVPT, and OVPT, even if they produced zero in one of those subcategories. We did not exclude these " 0 " data points because they provide meaningful information and are thus not missing at random. For example, if someone produced many action gestures but all of them were from an OVPT, then it is meaningful to know that they produced zero CVPT gestures. Similarly, if someone produced a lot of manner and path gestures but never combined both types of information in one gesture, then it is meaningful to know that they produced zero combined gestures. Given that there are several instances of missing data, linear mixed-effects models were used for analysis. The gesture dependent variables were predicted from the fixed effects of group and motion condition (and their interaction), with random intercepts for each participant. By-subject random slopes for motion were unidentifiable and could not be included because some participants had missing data in one motion condition.

\section{Results}

\section{Number of Words Produced}

Of the 37 Parkinson's patients, eight did not describe the lowmotion scene and three did not describe the high-motion scene. Of the 33 controls, four did not describe the low-motion scene, but all described the high-motion scene.

The number of words participants used to describe the scenes varied greatly (from 58 to 284 for the low-motion scene and from 23 to 242 for the high-motion scene). A linear mixed-effects model analyzed the effect of group (Parkinson's or control) and motion (high or low) on number of words spoken (see Table 2 for means and $S D$ s). A significant interaction between group and motion was found $(\beta=33.8, S E=12.03, d f=60.3, t=2.81, p=.007)$. Controls used significantly more words than Parkinson's patients in the low-motion condition $(\beta=47, S E=12.9, d f=104.7, t=$ $3.66, p<.001)$ but not in the high-motion condition $(\beta=13.2$, $S E=12.2, d f=96.4, t=1.08, p=.28$ ). The number of verbs and prepositions per 100 words of speech were also analyzed. For verbs, there was no effect of group $(\beta=.14, S E=.58, d f=$ $105.37, t=.23, p=.82)$ or motion $(\beta=.66, S E=.46, d f=$ $56.52, t=1.44, p=.16)$, and no interaction $(\beta=.65, S E=.66$, $d f=59.56, t=.99, p=.33)$. Similarly for prepositions there was no effect of group $(\beta=.38, S E=.56, d f=120.44, t=.68, p=$ $.45)$ and no interaction $(\beta=1.07, S E=.79, d f=64.9, t=1.36$, 
Table 2

Means (SD) for All Outcome Variables

\begin{tabular}{|c|c|c|c|c|c|c|c|c|}
\hline \multirow[b]{2}{*}{ Outcome variables } & \multicolumn{2}{|c|}{ Parkinson's disease } & \multirow[b]{2}{*}{$N$} & \multirow[b]{2}{*}{ High-motion } & \multicolumn{2}{|r|}{ Control } & \multirow[b]{2}{*}{$N$} & \multirow[b]{2}{*}{ High-motion } \\
\hline & $N$ & Low-motion & & & $N$ & Low-motion & & \\
\hline Words spoken & 29 & $123.83(40.34)$ & 34 & $109.03(39.39)$ & 29 & $175.35(74.15)$ & 33 & $121.06(43.63)$ \\
\hline Verbs spoken & 29 & $7.72(2.06)$ & 34 & $7.83(2.8)$ & 29 & $8.57(2.37)$ & 33 & $7.95(2.22)$ \\
\hline Prepositions spoken & 29 & $7.28(2.56)$ & 34 & $6.34(2.1)$ & 29 & $7.97(2.34)$ & 33 & $5.94(2.2)$ \\
\hline Overall gestures & 29 & $10.54(6.48)$ & 34 & $12.14(6.74)$ & 29 & $12.62(6.64)$ & 33 & $14.43(6.09)$ \\
\hline Representational (\%) & 26 & $67.42 \%$ & 34 & $82.01 \%$ & 26 & $70.03 \%$ & 33 & $80.67 \%$ \\
\hline Nonrepresentational (\%) & 26 & $32.58 \%$ & 34 & $17.99 \%$ & 26 & $29.97 \%$ & 33 & $19.33 \%$ \\
\hline Action gestures & 26 & $3.79(2.46)$ & 34 & $4.37(2.81)$ & 26 & $5.21(2.08)$ & 33 & $5.20(2.09)$ \\
\hline Manner gestures & 26 & $2.64(1.99)$ & 32 & $2.18(1.9)$ & 25 & $3.68(1.81)$ & 33 & $3.58(2.1)$ \\
\hline Path gestures & 26 & $1.95(1.25)$ & 32 & $3.13(1.77)$ & 25 & $3.38(1.55)$ & 33 & $3.46(1.63)$ \\
\hline Manner + path gestures & 26 & $.83(.92)$ & 32 & $.66(.74)$ & 25 & $1.67(1.26)$ & 33 & $1.84(1.53)$ \\
\hline Character viewpoint gestures & 26 & $2.49(2.02)$ & 32 & $.9(1.26)$ & 25 & $3.44(1.77)$ & 33 & $1.86(1.81)$ \\
\hline Observer viewpoint gestures & 26 & $1.29(1.3)$ & 32 & $3.74(2.11)$ & 25 & $1.98(1.21)$ & 33 & $3.34(1.73)$ \\
\hline
\end{tabular}

Note. Each variable (aside from Words spoken which is simply the total number of words used to describe each scene on average) is measured in the number of that type of gesture (or part of speech) produced per 100 words of speech, on average. The classification of gestures as representational and nonrepresentational is instead given in percentages. $N$ is the number of participants with data points for the corresponding analysis. Data points were missing when, for example, participants failed to describe a scene during their narration (see Data Analysis section for further information).

$p=.18)$, while a main effect of motion was observed $(\beta=2.03$, $S E=.56, d f=61.25, t=3.63, p<.001)$. More prepositions were produced in the low-motion narratives.

\section{Overall Rate of Gesture Production}

In addition to the participants who completely omitted the low-motion scene during their narration, three Parkinson's patients and three controls did not produce any gestures in the low-motion condition. All participants who described the high-motion scene gestured during it. Participants who described a scene but did not gesture were included in this analysis with a gesture rate of zero. A linear mixed-effects model analyzed the effect of group (Parkinson's or control) and motion (high or low) on overall gesture rate (see Table 2 for means and $S D$ s). There was no effect of group $(\beta=2.17, S E=1.59, d f=78, t=1.36, p=.18)$ or motion $(\beta=$ $1, S E=.7, d f=53.07, t=1.43, p=.16)$, and no interaction $(\beta=$ $.47, S E=1.01, d f=54.22, t=.47, p=.64)$.

\section{Gesture Types}

Representational gestures were produced more often than nonrepresentational gestures by both groups, and in both conditions (see Table 2). A linear mixed-effects model analyzed the effect of group (Parkinson's or control) and motion (high or low) on the proportion of gestures which were representational. A main effect of motion was found $(\beta=10.24, S E=3.4, d f=57.75, t=3.01, p=.004)$. Both groups produced more representational gestures for the high-motion relative to the low-motion scene. There was no effect of group $(\beta=$ $1.18, S E=3.96, d f=104.45, t=.3, p=.77)$ and no interaction $(\beta=$ 3.64, $S E=4.83, d f=60.08, t=.75, p=.45)$.

\section{Rate of Action Gesture Production}

A linear mixed-effects model tested the effects of group and motion on the rate of action gesture production (see Table 2 for means and $S D \mathrm{~s})$. There was no effect of group $(\beta=.86, S E=.6$, $d f=83.22, t=1.44, p=.15)$ or motion $(\beta=.09, S E=.4, d f=$
45.78, $t=.22, p=.83)$, and no interaction $(\beta=.26, S E=.57$, $d f=47.3, t=.47, p=.64)$.

\section{Manner and Path Action Gestures}

\section{Action Gestures Depicting Manners of Motion}

A linear mixed-effects model examined the effects of group and motion (low and high) on the number of gestures depicting manner of motion produced per 100 words of speech (see Table 2 for means and $S D$ s). A significant effect of group was found $(\beta=$ 1.42, $S E=.48, d f=85.87, t=2.91, p=.004)$. People with Parkinson's gestured manner information at a lower rate than controls in the high-motion condition $(\beta=1.42, S E=.49, d f=$ $87.1, t=2.91, p=.005)$, while there was no difference between the groups in the low-motion condition $(\beta=.71, S E=.53, d f=$ 99.9, $t=1.35, p=.18$; see Figure 1$)$.

\section{Action Gestures Depicting Paths of Motion}

A linear mixed-effects model examined the effects of group and motion on the number of gestures depicting paths of motion produced per 100 words of speech (see Table 2). There was no main effect of group $(\beta=.36, S E=.4, d f=96.5, t=.91, p=$ $.36)$ or motion $(\beta=.16, S E=.34, d f=44.5, t=.48, p=.64)$, and no interaction $(\beta=.86, S E=.48, d f=45.65, t=1.78, p=$ .08 ; see Figure 1).

\section{Action Gestures Combining Manner and Path}

A linear mixed-effects model examined the effects of group and motion on the number of gestures combining manner and path produced per 100 words of speech (see Table 2). A main effect of group was found $(\beta=1.18, S E=.29, d f=108.89, t=4.11, p<$ $.001)$. Controls produced significantly more combined manner and path gestures than the Parkinson's group in both the low- $(\beta=.8$, $S E=.33, d f=111, t=2.45, p=.016)$ and the high-motion condition $(\beta=1.18, S E=.29, d f=109, t=4.11, p<.001$; see Figure 2). 
Figure 1

The Number of Path and Manner Gestures per 100 Words Produced by Each Group and for Each Motion Condition
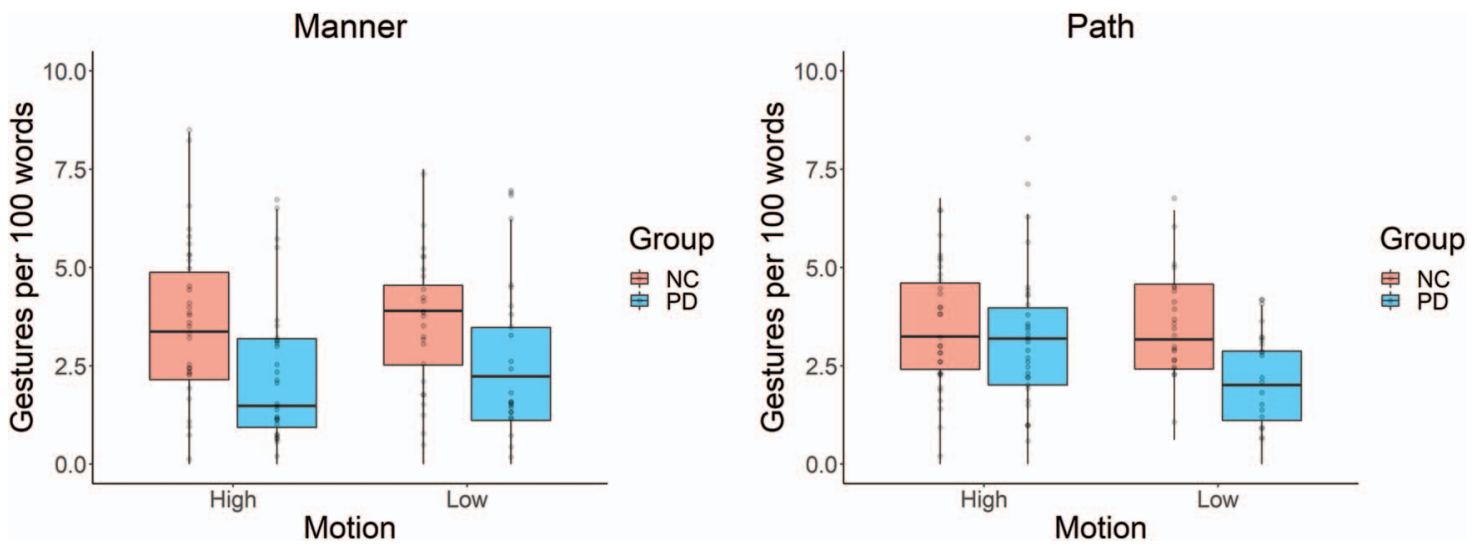

Note. Boxplots indicate the minimum, maximum, median, and first and third quartiles. Jittered data points display the gesture rate from each individual participant. See the online article for the color version of this figure.

\section{Action Gesture Viewpoint}

A linear mixed-effects model examined the effects of group and motion on the number of CVPT gestures produced per 100 words of speech (see Table 2). A main effect of motion was found $(\beta=$ $1.33, S E=.29, d f=54.38, t=4.65, p<.001)$. CVPT gestures occurred more often in the low-motion than the high-motion condition. A main effect of group was also found $(\beta=.97, S E=$ $.42, d f=89.09, t=2.33, p=.02$ ). People with Parkinson's produced CVPT gestures at a lower rate than controls in the high-motion condition $(\beta=.97, S E=.42, d f=87.2, t=2.32$,

\section{Figure 2}

The Number of Combined Manner Plus Path Gestures per 100 Words Produced by Each Group and for Each Motion Condition

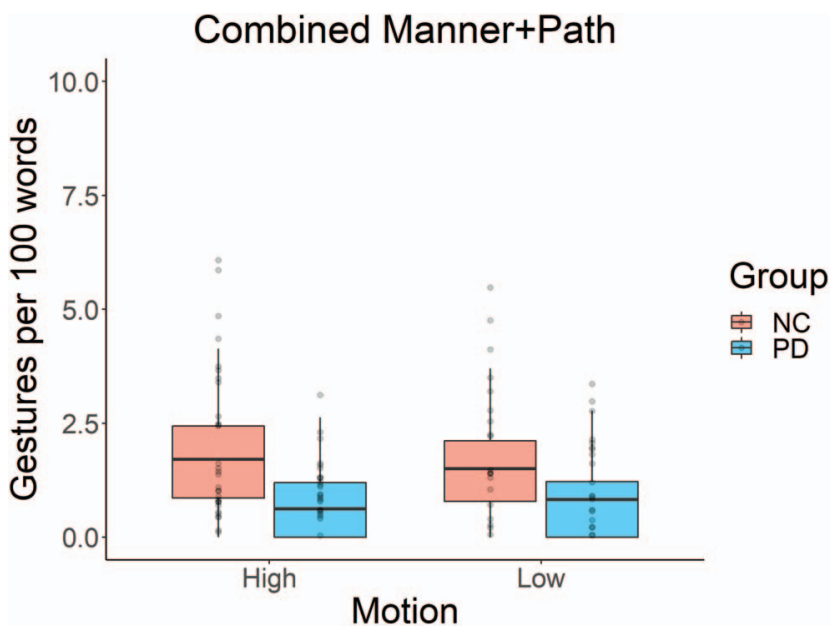

Note. Boxplots indicate the minimum, maximum, median, and first and third quartiles. Jittered data points display the gesture rate from each individual participant. See the online article for the color version of this figure. $p=.02)$, but there was no significant difference between the groups in the low-motion condition $(\beta=.67, S E=.45, d f=100$, $t=1.48, p=.14$; see Figure 3).

This analysis was repeated for OVPT gestures. A significant effect of motion was found $(\beta=1.32, S E=.31, d f=37.02, t=$ $4.24, p<.001)$. OVPT gestures occurred more often in the high-motion than the low-motion condition (see Table 2). There was no significant effect of group $(\beta=.38, S E=.43, d f=77.65$, $t=.87, p=.39)$ and no interaction $(\beta=.8, S E=.44, d f=37.86$, $t=1.82, p=.08$; see Figure 3).

The results of the manner and viewpoint analyses are similar: People with Parkinson's produced fewer manner gestures and fewer gestures from a CVPT, and these effects seems to be driven by the high-motion condition specifically. Given that CVPT action gestures (at least in this dataset) necessarily depicted manner, it is reasonable to ask if these two analyses are essentially describing the same effect. We calculated the proportion of manner gestures produced from a CVPT and OVPT by each group in each motion condition (see Table 3 ). In the low-motion condition, the majority of manner gestures in both groups occurred from a CVPT. However, in the high-motion condition, manner gestures were produced from both perspectives, and in fact more often occurred from an OVPT.

To test this further, we examined the relationship between viewpoint and manner. In this dataset, all CVPT action gestures necessarily depicted manner information. However, OVPT gestures could include manner information or they could depict only path. We calculated the number of OVPT gestures with and without manner information produced by each group in each motion condition. For OVPT gestures that included manner, a linear-mixed effects model revealed a significant effect of motion $(\beta=1.44, S E=.22, d f=40.88, t=6.55, p<$ $.001)$, but no effect of group $(\beta=.45, S E=.27, d f=89.14, t=1.64$, $p=.11)$ and no interaction $(\beta=.43, S E=.31, d f=41.89, t=1.37$, $p=.18)$. Both groups produced more OVPT manner gestures in the high-motion condition than they did in the low-motion condition (see Figure 4). For OVPT path-only gestures, there was a significant interaction between group and motion $(\beta=1.45, S E=.46, d f=$ 48.25, $t=3.12, p=.003$ ). People with Parkinson's produced 
Figure 3

The Number of OVPT and CVPT Gestures Produced per 100 Words by Each Group and for Each Motion Condition
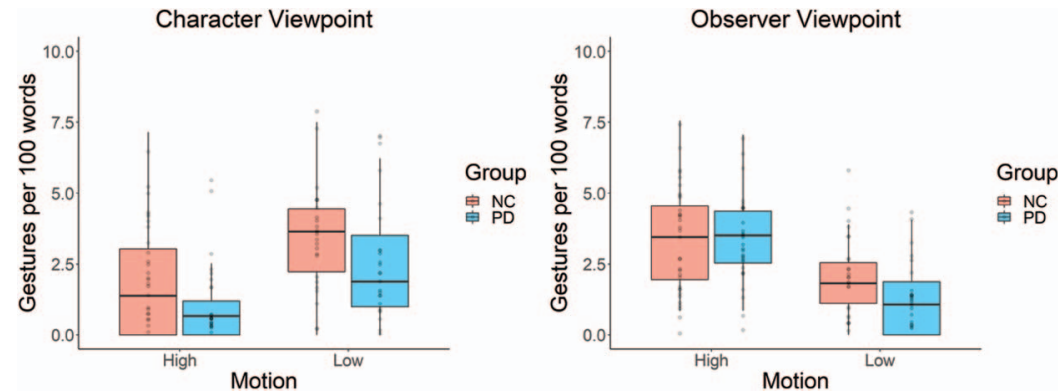

Note. Boxplots indicate the minimum, maximum, median, and first and third quartiles. Jittered data points display the gesture rate from each individual participant. See the online article for the color version of this figure.

significantly more OVPT path-only gestures than controls in the high-motion condition $(\beta=.84, S E=.32, d f=112, t=2.66$, $p=.009)$, but there was no group difference in the low-motion condition $(\beta=.61, S E=.36, d f=112, t=1.69, p=.09$; see Figure 4).

The overall observed group difference in manner gesture production includes all manner gestures produced from both a CVPT and an OVPT. When splitting by viewpoint, the group difference is smaller but still significant in the CVPT gestures (all manner), while it is not observed in the OVPT manner gestures. Figure 5 shows overall, CVPT, and OVPT manner gesture production side by side for comparison. Differences in CVPT gesture production make a larger contribution than OVPT gestures to the overall group differences in manner gesture production. However, the effect in total manner gestures $(\beta=1.42)$ was larger than the effect in only CVPT manner gestures $(\beta=.97)$, suggesting that OVPT manner gestures contributed to the manner effects observed, albeit to a lesser extent than the CVPT manner gestures.

\section{Follow-Up Manner-Verb Analysis}

To briefly summarize the results thus far, we found that Parkinson's disease patients produced fewer manner gestures and CVPT gestures than controls, particularly when describing high-motion actions. In line with our predictions, this may indicate that Parkinson's disease patients are less able to imagine the motor features of high-motion actions from a first-person perspective. How-

Table 3

The Proportion of Manner Gestures Produced From Each Viewpoint

\begin{tabular}{ccr}
\hline Condition \& viewpoint & Parkinson's disease & Control \\
\hline Low-motion & & \\
Manner \& CVPT & $92.23 \%$ & $92.98 \%$ \\
Manner \& OVPT & $7.02 \%$ & $7.77 \%$ \\
High-motion & & \\
Manner \& CVPT & $38.71 \%$ & $46.26 \%$ \\
Manner \& OVPT & $61.29 \%$ & $53.74 \%$ \\
\hline
\end{tabular}

Note. $\mathrm{CVPT}=$ character viewpoint; OVPT $=$ observer viewpoint. ever, a potential alternative explanation of these findings is that gestural movements may simply be easier to produce when they only represent path and not manner, and easier movements may be preferred by Parkinson's disease patients. That is, the impairment may be praxic rather than cognitive. On the other hand, if this alternative hypothesis were true, one would expect manner gestures to be equally affected in both conditions. The fact that we observe a reduction in manner and CVPT gesture production only in the high-motion condition argues against this explanation.

To investigate this possible alternative hypothesis, we conducted additional post hoc exploratory analyses that examined the concurrent speech produced with participants' action gestures. We reasoned that if people with Parkinson's disease drop manner information from their gestures only because it makes them physically less taxing to produce, but the underlying motor imagery remains rich and intact, they would produce a greater number of speech-gesture units where manner information was present in speech, but absent in gesture. To test this, we identified the speech units produced during all action gestures.

Speech units were segmented at the level of the semantic idea being communicated (Butterworth, 1975). Semantic units were identified starting with the speech being produced for the duration of the gesture. If a semantic idea was already in progress when the gesture started, or completed after the gesture ended, we included the additional speech before and after the gesture. That is, the entire semantic speech unit was retained. In these speech units, we coded the spoken verbs as either semantically light (come, go, make, take, get, give, do, have, be, and put) or semantically heavy (all others, e.g., climb, run). Semantically light verbs do not contain information about the manner of a movement, whereas heavy verbs do. For example, the statement "he climbs up the pole" reveals information about the way the person moved up the pole, whereas the statement "he goes up the pole" does not.

We then calculated the proportion of manner-present and manner-absent action gestures produced with semantically light and heavy verbs for each subject. If people with Parkinson's disease maintained a normal level of manner information in speech while only missing manner information from the gesture modality, they would produce more units that contained heavy verbs together 
Figure 4

The Number of OVPT Gestures That Did Not Include Manner Information (Path-Only), and That Did Include Manner Information, Produced by Each Group for Each Motion Condition
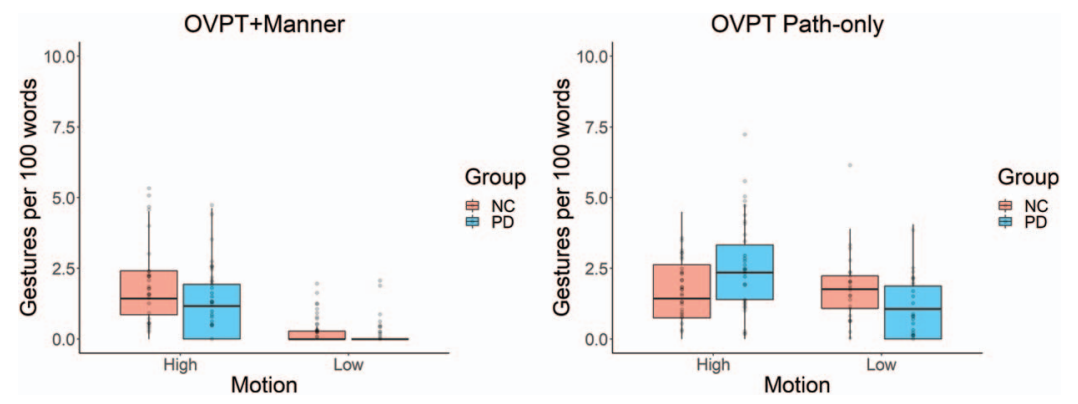

Note. Boxplots indicate the minimum, maximum, median, and first and third quartiles. Jittered data points display the gesture rate from each individual participant. See the online article for the color version of this figure.

with manner-absent gestures than controls. However, we found no group differences in the proportion of manner-absent gestures produced with semantically heavy verbs in either the low, $t(40)=$ $.81, p=.43, d=.25,95 \% \mathrm{CI}[-29.05,12.47]$ or high-motion, $t(55)=.65, p=.52, d=.18,95 \%$ CI [-26.15, 13.32] condition. Manner-absent gestures were produced with semantically heavy verbs approximately $46 \%$ of the time in Parkinson's disease patients and approximately $54 \%$ of the time in controls (see Table 4). Thus, the impairment in manner gesture production we observe in Parkinson's disease cannot be explained only by a physical difficulty in movement production.

\section{Discussion}

In this study, we examined how multiple features of gestures depicting actions (manner, path, and viewpoint) are affected by neurological damage to the motor system. Our investigation was based on gesture production models, according to which gestures are based on mental imagery, as well as evidence from cognitive neuroscience suggesting visual and motor imagery is based on reactivated visual and motor states in the brain. We predicted that if the imagery underlying action gestures requires the involvement of the motor system, action gesture production would be impaired in Parkinson's disease, and this impairment would be greater when patients described high-motion actions that require greater involvement of the motor system during simulation.

\section{Gesture Rate Is Largely Unimpaired in Early to Midstage Parkinson's Disease}

Given the profound effects that Parkinson's disease has on movement initiation, a straightforward prediction might be that people with Parkinson's would simply stop gesturing when they speak. However, we did not observe a reduction in either overall gesture use or action gesture use in Parkinson's disease, replicating a similar result from two previous studies (Cleary et al., 2011; Humphries et al., 2016). Nevertheless, overall verbal output was indeed lower in the patients, who used fewer words than controls to describe the events of the cartoon. Since people usually only gesture when they speak (although see "co-thought gestures": Chu $\&$ Kita, 2016), the raw number of gestures produced is typically normalized to the number of words produced. Thus, while verbal output was reduced in Parkinson's disease, gesture rate remained normal. In and of itself, this finding has important implications for speech and language therapy (SLT) in Parkinson's disease. For patients with dysarthria, gestures may be able to clarify the content of poorly articulated speech. The fact that people with Parkinson's gesture at a rate that is normal with respect to their verbal output indicates that gestures could be a useful target of SLT. The global standard for speech therapy in Parkinson's disease is the Lee Silverman Voice Treatment, referred to as LSVT LOUD (Ramig et al., 2001), which targets vocal loudness. A more recently developed treatment, LSVT BIG acknowledges that actions in Parkinson's disease become smaller in amplitude, and trains patients to produce bigger movements (Ebersbach et al., 2010). Particular attention to cospeech gestures as a way of compensating for dysarthria and contributing to more effective communication could be incorporated into both LSVT LOUD and LSVT BIG.

While we found no difference between the groups in the rate of gesture production, we did observe that both groups gestured more when describing high-motion actions compared to low-motion actions. This suggests that a greater level of motion content stimulates greater overall gesture production, which is a prediction made by the Gesture-as-Simulated-Action framework (Hostetter \& Alibali, 2008, 2019). Moreover, the proportional distribution of gesture types across the two motion conditions showed that both groups produced more representational and fewer nonrepresentational gestures during the high-motion condition, suggesting that the increase in gesture rate for the high-motion condition largely comprised an increased rate of representational gesture production. Overall, the processes that trigger increased gesture production in controls seem to be largely intact in Parkinson's disease, suggesting that gesture production remains inextricable from global speech production processes even in a movement-impaired population. This underlines the tight link between speaking and gesturing in human communication, at least regarding the domain of action information. 
Figure 5

A Comparison View of Manner Gesture Production: Total Manner Gestures, CVPT Manner Gestures, and OVPT Manner Gestures

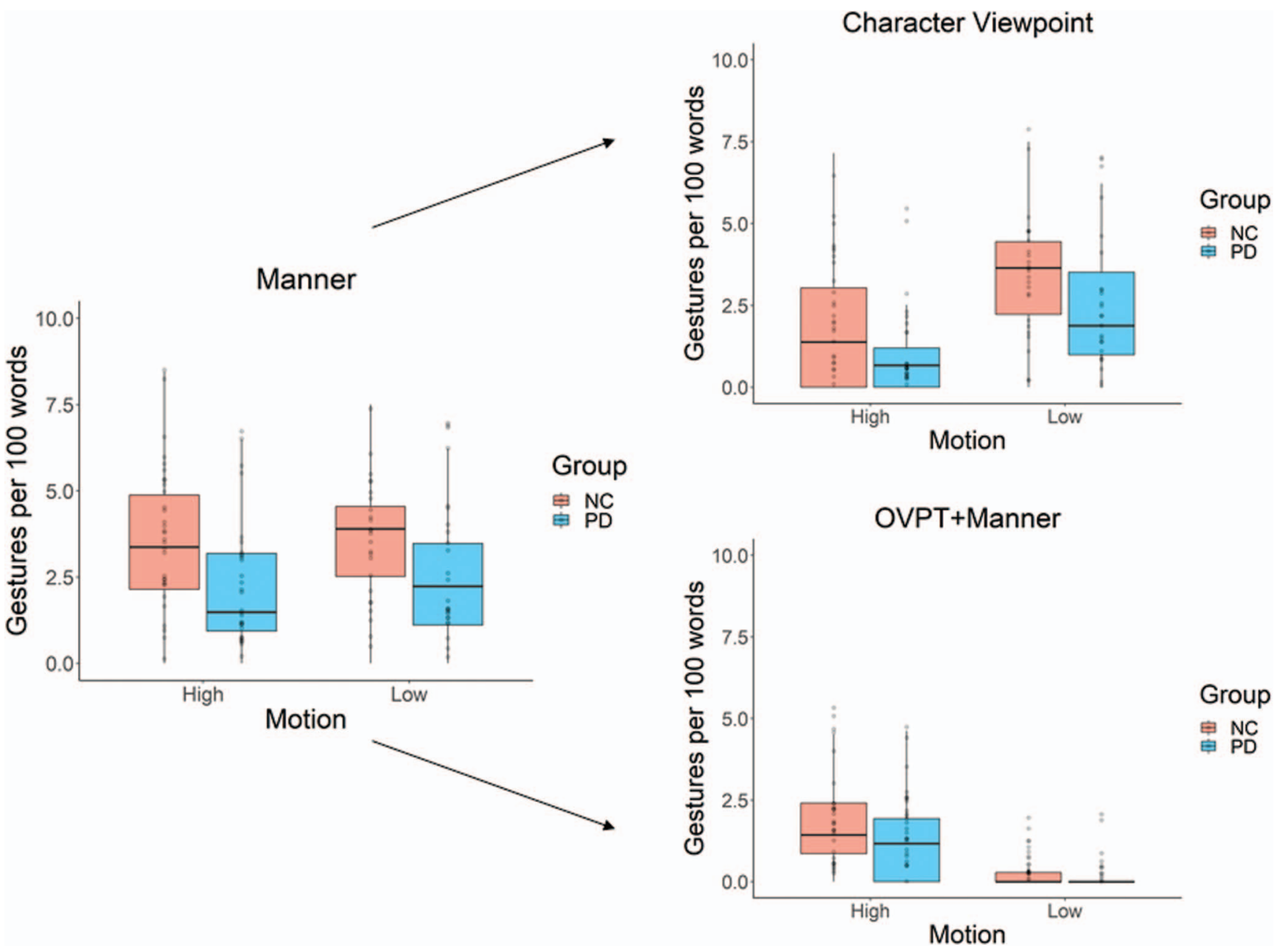

Note. Boxplots indicate the minimum, maximum, median, and first and third quartiles. Jittered data points display the gesture rate from each individual participant. See the online article for the color version of this figure.

The fact that the groups did not differ in their proportional use of representational and nonrepresentational gestures suggests that people with Parkinson's disease still use gesture to achieve largely the same communicative goals. Both groups produced fewer representational gestures, and correspondingly, more nonrepresentational (pragmatic) gestures during the low-motion scene, which can be attributed to the story content of this scene. In the low-motion condition, Sylvester is seen formulating a plot based on an overheard conversation but is ultimately foiled by the grandmother. In conveying this information, the speaker needs to explain what each character thinks and believes at certain points in time. Thus, there may have been a greater communicative need for speakers to use pragmatic gestures to emphasize key points and check understanding during the low-motion condition. This also explains why both groups used more words to describe the low-motion scene than the high-motion scene. Tantalizingly, the normal pragmatic gesturing pattern we observed in the Parkinson's group suggests that these participants were sensitive to the communicative needs of the situation, and to the perspective of their conver- sational partners. Capitalizing on these pragmatic functions of gestures could be an additional focus of Parkinson's disease SLT, and practitioners may want to consider how patients can maximize the benefits of the gesture modality. The present study focused on detailed analyses of representational gestures, but future studies may be able to provide more in-depth analyses of Parkinson's patients' use of pragmatic gestures, including how it compares to the use of pragmatic gestures by other patient groups. For example, an increased use of pragmatic gestures has been found in people with aphasia (Akhavan et al., 2018; Rose, 2006), while we found that people with Parkinson's appear to use pragmatic gestures at a similar level to controls.

\section{Motor Impairment Affects the Ability to Gesture About Manners of High-Motion Actions}

We examined how often speakers represented manner and path information in their action gestures and predicted that people with Parkinson's disease would be specifically impaired in the produc- 
Table 4

Percentage of Action Gesture Units in Which Manner Information Was Present and Absent, Produced Together With Manner in Speech (Heavy Verbs) and Without Manner in Speech (Light Verbs)

\begin{tabular}{lcc}
\hline Type of speech-gesture unit & Parkinson's disease & Controls \\
\hline Low-motion & & \\
Manner absent + heavy verb & $\mathbf{4 5 . 2 6 \%}$ & $\mathbf{5 3 . 5 5 \%}$ \\
Manner absent + light verb & $54.74 \%$ & $46.45 \%$ \\
Manner present + heavy verb & $73.01 \%$ & $61.95 \%$ \\
Manner present + light verb & $26.99 \%$ & $38.05 \%$ \\
High-motion & & \\
Manner absent + heavy verb & $\mathbf{4 7 . 9 9 \%}$ & $\mathbf{5 4 . 4 \%}$ \\
Manner absent + light verb & $52.01 \%$ & $45.6 \%$ \\
Manner present + heavy verb & $87.44 \%$ & $89.5 \%$ \\
Manner present + light verb & $12.56 \%$ & $10.5 \%$ \\
\hline
\end{tabular}

Note. Percentages refer to each group in each subsection. Critical information is in the top row for each motion condition (in bold). If Parkinson's patients dropped manner information from their gestures while maintaining an intact motor concept in speech, they would produce more units where manner was present in speech (heavy verbs) but absent in gesture. In fact, controls produced more instances of this kind, though there were no significant differences between the groups.

tion of manner information, but not path information. This prediction was derived from the hypothesis that gesturing manner information would necessarily depend on imagery of the motor features of actions, while gesturing path information could rely on visual imagery that would not necessarily recruit the motor system. In addition, we predicted that the Parkinson's disease group would be more impaired in gesturing manner information when the actions being described involved a greater degree of bodily motion. Consistent with our predictions, we found that the Parkinson's disease group produced significantly fewer manner gestures than controls, but only in the high-motion condition. This result suggests that that people with mild-moderate Parkinson's disease are still able to simulate low-motion actions (such as answering the telephone and knocking on a door) but have difficulty simulating high-motion actions (such as climbing and jumping), which may no longer be within their motor repertoire. As predicted by gesture theories that hypothesize a role for motor simulations in action gesture production, manner information may require an intact simulation of the motor features of the action in order for this information to be represented in a gesture. If the person fails to simulate manner information, we propose that they also fail to gesture about it. Manner information is expressed in language with verbs and it has previously been demonstrated that people with Parkinson's have more difficulty naming high-motion action verbs than they do low-motion action verbs (Herrera, Rodríguez-Ferreiro, et al., 2012; Humphries et al., 2016, although see counter evidence reported in Humphries et al., 2019). Our finding corroborates the notion that the motor system is more involved in representing high-motion than low-motion actions.

The manner and path gesture analysis also revealed that controls combined manner and path into a single gesture more often than Parkinson's patients. Previously, Cleary et al. (2011) also demonstrated that people with Parkinson's disease were less likely to include two components of action information in one gesture than were controls. The simultaneous encoding of both the manner features of the action as well as the figure's path through space, within a single gesture, may reflect a more detailed underlying representation. Representing both elements at the same time may be too cognitively demanding for those with Parkinson's disease, causing them to deconstruct the motion features into component parts (McNeill, 2012). Executive control studies have shown that Parkinson's disease leads to a specific difficulty in dual tasking, which is thought to be caused by limited attentional resources, reduced automaticity in processing, and impaired executive function (Wu \& Hallett, 2008).

\section{Gesturing About Actions From a First-Person Perspective Depends on the Integrity of the Extrapyramidal Motor System}

We previously found that people with Parkinson's disease produce a significantly lower proportion of their action gestures from a character's viewpoint, or CVPT (Humphries et al., 2016). In the present study we replicated and extended this finding by demonstrating that CVPT gesture production in Parkinson's disease is modulated by the bodily motion content of the actions being described. The Parkinson's disease group produced CVPT gestures at a similar rate as controls when describing low-motion actions, but they produced significantly fewer CVPT gestures than controls in the high-motion condition. As argued in Humphries et al. (2016), a reduction in the use of CVPT gestures may reflect a difficulty in simulating the viewed action from a first-person perspective. The fact that this effect appears to be modulated by motion content in Parkinson's disease supports the view that there is greater involvement of the motor system in representing highmotion than low-motion actions (Herrera, Rodríguez-Ferreiro, et al., 2012). In addition, the fact that the Parkinson's disease group produced CVPT gestures at a normal rate when describing lowmotion action content is in line with evidence from previous studies suggesting that the nature of the action to be simulated is critical for Parkinson's disease patients. Easier movements that require less bodily motion may still be possible for Parkinson's disease patients to simulate kinesthetically, and thus gesture about from a first-person perspective (Castiello et al., 2009; Helmich et al., 2007; Herrera \& Cuetos, 2012).

A limitation of this study is that the saliency of manner and path information may have differed between the low- and high-motion scenes. For example, the low-motion scene featured more interactions between characters, and path information here may have been less salient than in the fast-paced chase scene featured in the high-motion condition. A consequence that should be noted is that both groups produced fewer CVPT gestures in the high-motion condition than in the low-motion condition. We believe this is partly due to an artifact of the stimulus material that we had not accounted for. At the beginning of the high-motion scene, Sylvester climbs up a telegraph pole, and most of the subsequent action in the scene takes place on the overhead wires. Consequently, Sylvester's height on the vertical plane is a salient feature of the motion event and is easily depicted in gesture by using the hand to depict Sylvester (in OVPT fashion) and elevating the hand above head height to demonstrate his position in the vertical plane in relation to the ground. It is less straightforward to depict this salient positional information using CVPT gestures, which we believe contributed to why both groups generally preferred the OVPT in this condition. Overall, while the conditions were not perfectly matched in 
the relative salience of manner and path information, any differences in conditions affected both groups. It is notable that, while path information may have been more salient in the high-motion condition, controls still produced significantly more manner gestures than Parkinson's patients in this condition. In fact, controls produced very similar numbers of path and manner gestures in both conditions, regardless of any biasing effects of the stimuli.

Since CVPT action gestures in this dataset always included manner information, we examined whether the observed manner and CVPT effects described the same pattern in the data. As pointed out in the Introduction, we expected a certain degree of overlap between manner and CVPT gestures. While CVPTmanner gestures differed significantly between the groups, OVPTmanner gestures did not, suggesting that the reduction in CVPT gesture use contributed to the observed differences in manner gesture production to a greater extent than OVPT-manner gestures. However, the largest effect was observed in the manner analysis that combined gestures produced from viewpoints, suggesting that the OVPT-manner gestures did contribute to this result.

While OVPT-manner gesture use was not significantly different between the groups, people with Parkinson's produced significantly more path-only OVPT gestures than controls, specifically in the high-motion condition. This result is remarkable in that this was the only type of gesture use that was significantly increased in Parkinson's, and implies that as the production of manner and CVPT gestures decreased in Parkinson's disease during highmotion, the production of OVPT path gestures increased. This may imply a compensatory mechanism, where people with Parkinson's disease rely more on visual imagery when motor imagery is impaired. As discussed earlier, when people with Parkinson's disease perform a task that usually depends on motor imagery, they have been found to rely on third-person visual features by recruiting regions of posterior parietal and occipital cortex (Helmich et al., 2007; van Nuenen et al., 2012). Similar posterior parietal regions are involved in representing paths of motion (Amorapanth et al., 2010; Baciu et al., 1999; Noordzij et al., 2008). The increased production of path gestures by people with Parkinson's disease when talking about high-motion actions may mean that the patient compensates for a failure to simulate the kinematics of the action from a first-person perspective by instead simulating the action's visual features (e.g., where the figure moves in space). This proposed compensatory mechanism is similar to the mechanism suggested by mental hand rotation research, where Parkinson's patients recruit the extrastriate body area (known to respond to third-person views of bodies) during a task that normally involves motor imagery, to compensate for a function normally performed by the dorsal premotor cortex (Helmich et al., 2007). The importance of visual aspects of motor imagery in Parkinson's disease has also been emphasized by a recent study in which the imitation of hand movements by Parkinson's patients was influenced by imagining actions while simultaneously observing them. This effect was related to the self-reported vividness of visual, but not kinesthetic imagery in the Parkinson's disease group, but the opposite effect was found in the control group (Bek et al., 2019).

\section{Conclusions}

In this study, we tested the hypothesis that the motor system necessarily contributes to motor imagery, and that gesture produc- tion relies on this motor imagery. We investigated how gestural depictions of actions are affected in Parkinson's disease, by considering manner of motion, path of motion, and the visual perspective from which action gestures were produced. Our findings suggest that the overall rate of gesture production is relatively spared, while manners of motion and first-person action gestures are particularly vulnerable in Parkinson's disease when the action being depicted involves a greater degree of bodily motion. This dissociation between gesture rate and gesture content suggests a differential role for imagery at different stages of gesture production processes. We suggest that gesture rate is largely determined by speech production processes, with Parkinson's disease patients gesturing at a normal rate relative to their verbal output, despite an impairment in self-initiated movements. On the other hand, gesture content appears to be shaped by a simulation of the event to be described. This proposal contrasts with predictions set out by the GSA framework; namely, that motor simulations should affect gesture rate as well as gesture form (Hostetter \& Alibali, 2008, 2019). The fact that people with Parkinson's disease gesture at a normal rate despite changes in the way they produce and represent actions suggests that gesture production models that postulate a global role of motor imagery/simulation may need to incorporate finer-grained distinctions between the different aspects of the gesture production process. We propose that the egocentric, kinesthetic features of high-motion actions require greater involvement of the frontal cortical-subcortical motor network in their representation than low-motion actions. The failure to represent these features in gesture is accompanied by a corresponding increase in third-person, visual path gestures, which may reflect a compensatory mechanism. The findings of this study strongly support the hypothesis that gestures are shaped by underlying motor imagery, and have implications for our understanding of how Parkinson's disease changes everyday communication. The fact that gesture rate is relatively spared in Parkinson's disease hints at the potential to target gesture production in speech and language therapy to help patients compensate for dysarthria. Overall, this study offers an example of how patient studies continue to make powerful theoretical contributions to our understanding of the neural underpinnings of cognitive and behavioral processes.

\section{References}

Akhavan, N., Göksun, T., \& Nozari, N. (2018). Integrity and function of gestures in aphasia. Aphasiology, 32(11), 1310-1335. https://doi.org/10 .1080/02687038.2017.1396573

Alexander, G. E., \& Crutcher, M. D. (1990). Functional architecture of basal ganglia circuits: Neural substrates of parallel processing. Trends in Neurosciences, 13(7), 266-271. https://doi.org/10.1016/01662236(90)90107-L

Amick, M. M., Schendan, H. E., Ganis, G., \& Cronin-Golomb, A. (2006). Frontostriatal circuits are necessary for visuomotor transformation: Mental rotation in Parkinson's disease. Neuropsychologia, 44(3), 339 349. https://doi.org/10.1016/j.neuropsychologia.2005.06.002

Amorapanth, P. X., Widick, P., \& Chatterjee, A. (2010). The neural basis for spatial relations. Journal of Cognitive Neuroscience, 22(8), 1739_ 1753. https://doi.org/10.1162/jocn.2009.21322

Baciu, M., Koenig, O., Vernier, M.-P., Bedoin, N., Rubin, C., \& Segebarth, C. (1999). Categorical and coordinate spatial relations: fMRI evidence for hemispheric specialization. NeuroReport, 10(6), 1373-1378. https:// doi.org/10.1097/00001756-199904260-00040

Barsalou, L. W., Santos, A., Simmons, W. K., \& Wilson, C. D. (2008). 
Language and simulation in conceptual processing. In M. de Vega, A. Glenberg, \& A. Graesser (Eds.), Symbols and embodiment: Debates on meaning and cognition (pp. 245-283). Oxford University Press.

Bartolo, A., Cubelli, R., Della Sala, S., \& Drei, S. (2003). Pantomimes are special gestures which rely on working memory. Brain and Cognition, 53(3), 483-494. https://doi.org/10.1016/S0278-2626(03)00209-4

Baudrexel, S., Witte, T., Seifried, C., von Wegner, F., Beissner, F., Klein, J. C., Steinmetz, H., Deichmann, R., Roeper, J., \& Hilker, R. (2011). Resting state fMRI reveals increased subthalamic nucleus-motor cortex connectivity in Parkinson's disease. NeuroImage, 55(4), 1728-1738. https://doi.org/10.1016/j.neuroimage.2011.01.017

Bek, J., Gowen, E., Vogt, S., Crawford, T. J., \& Poliakoff, E. (2019). Combined action observation and motor imagery influences hand movement amplitude in Parkinson's disease. Parkinsonism \& Related Disorders, 61, 126-131. https://doi.org/10.1016/j.parkreldis.2018.11.001

Bocanegra, Y., García, A. M., Lopera, F., Pineda, D., Baena, A., Ospina, P., Alzate, D., Buriticá, O., Moreno, L., Ibáñez A., \& Cuetos, F. (2017). Unspeakable motion: Selective action-verb impairments in Parkinson's disease patients without mild cognitive impairment. Brain \& Language, 168, 37-46. https://doi.org/10.1016/j.bandl.2017.01.005

Bocanegra, Y., García, A. M., Pineda, D., Buriticá, O., Villegas, A., Lopera, F., Gómez, D., Gómez-Arias, C., Cardona, J. F., Trujillo, N., \& Ibáñez, A. (2015). Syntax, action verbs, action semantics, and object semantics in Parkinson's disease: Dissociability, progression, and executive influences. Cortex, 69, 237-254. https://doi.org/10.1016/j.cortex .2015 .05 .022

Boulenger, V., Mechtouff, L., Thobois, S., Broussolle, E., Jeannerod, M., \& Nazir, T. A. (2008). Word processing in Parkinson's disease is impaired for action verbs but not for concrete nouns. Neuropsychologia, 46(2), 743-756. https://doi.org/10.1016/j.neuropsychologia.2007.10.007

Buhmann, C., Glauche, V., Stürenburg, H. J., Oechsner, M., Weiller, C., \& Büchel, C. (2003). Pharmacologically modulated fMRI-Cortical responsiveness to levodopa in drug-naive hemiparkinsonian patients. Brain: A Journal of Neurology, 126(2), 451-461. https://doi.org/10 .1093/brain/awg033

Butterworth, B. (1975). Hesitation and semantic planning in speech. Journal of Psycholinguistic Research, 4(1), 75-87. https://doi.org/10.1007/ BF01066991

Carpenter, P. A., Just, M. A., Keller, T. A., Eddy, W., \& Thulborn, K. (1999). Graded functional activation in the visuospatial system with the amount of task demand. Journal of Cognitive Neuroscience, 11(1), 9-24. https://doi.org/10.1162/089892999563210

Castiello, U., Ansuini, C., Bulgheroni, M., Scaravilli, T., \& Nicoletti, R. (2009). Visuomotor priming effects in Parkinson's disease patients depend on the match between the observed and the executed action. Neuropsychologia, 47(3), 835-842. https://doi.org/10.1016/j.neuropsychologia.2008.12.016

Chan, A. W. Y., Peelen, M. V., \& Downing, P. E. (2004). The effect of viewpoint on body representation in the extrastriate body area. NeuroReport, 15(15), 2407-2410. https://doi.org/10.1097/00001756-20041025000021

Chatterjee, A. (2008). The neural organization of spatial thought and language. Seminars in Speech and Language, 29(3), 226-238. https:// doi.org/10.1055/s-0028-1082886

Chu, M., \& Kita, S. (2016). Co-thought and co-speech gestures are generated by the same action generation process. Journal of Experimental Psychology: Learning, Memory, and Cognition, 42(2), 257-270. https:// doi.org/10.1037/xlm0000168

Cleary, R. A., Poliakoff, E., Galpin, A., Dick, J. P. R., \& Holler, J. (2011). An investigation of co-speech gesture production during action description in Parkinson's disease. Parkinsonism \& Related Disorders, 17(10), 753-756. https://doi.org/10.1016/j.parkreldis.2011.08.001
Cook, S. W., \& Tanenhaus, M. K. (2009). Embodied communication: Speakers' gestures affect listeners' actions. Cognition, 113(1), 98-104. https://doi.org/10.1016/j.cognition.2009.06.006

Corballis, M. C. (1997). Mental rotation and the right hemisphere. Brain and Language, 57(1), 100-121. https://doi.org/10.1006/brln.1997.1835

Cotelli, M., Borroni, B., Manenti, R., Zanetti, M., Arévalo, A., Cappa, S. F., \& Padovani, A. (2007). Action and object naming in Parkinson's disease without dementia. European Journal of Neurology, 14(6), 632637. https://doi.org/10.1111/j.1468-1331.2007.01797.x

Cronin-Golomb, A., \& Amick, M. (2001). Spatial abilities in aging, Alzheimer's disease, and Parkinson's disease. In F. Boller \& J. Grafman (Eds.), Handbook of neuropsychology (Vol. 6, pp. 119-144). Elsevier.

de Ruiter, J. P. (2000). The production of gesture and speech. In D. Mc Neill (Ed.), Language and gesture (pp. 284-311). Cambridge University Press. https://doi.org/10.1017/CBO9780511620850.018

Dominey, P., Decety, J., Broussolle, E., Chazot, G., \& Jeannerod, M. (1995). Motor imagery of a lateralized sequential task is asymmetrically slowed in hemi-Parkinson's patients. Neuropsychologia, 33(6), 727741. https://doi.org/10.1016/0028-3932(95)00008-Q

Dumont, C., Ska, B., \& Schiavetto, A. (1999). Selective impairment of transitive gestures: An unusual case of apraxia. Neurocase, 5(5), 447458. https://doi.org/10.1080/13554799908402739

Ebersbach, G., Ebersbach, A., Edler, D., Kaufhold, O., Kusch, M., Kupsch, A., \& Wissel, J. (2010). Comparing exercise in Parkinson's diseaseThe Berlin BIG Study. Movement Disorders, 25(12), 1902-1908. https:// doi.org/10.1002/mds.23212

Fernandino, L., Conant, L. L., Binder, J. R., Blindauer, K., Hiner, B., Spangler, K., \& Desai, R. H. (2013). Parkinson's disease disrupts both automatic and controlled processing of action verbs. Brain and Language, 127(1), 65-74. https://doi.org/10.1016/j.bandl.2012.07.008

Feyereisen, P., \& Havard, I. (1999). Mental imagery and production of hand gestures while speaking in younger and older adults. Journal of Nonverbal Behavior, 23(2), 153-171. https://doi.org/10.1023/A: 1021487510204

Ganis, G., Keenan, J., Kosslyn, S., \& Pascual-Leone, A. (2000). Transcranial magnetic stimulation of primary motor cortex affects mental rotation. Cerebral Cortex, 10(2), 175-180. https://doi.org/10.1093/cercor/10 .2 .175

Göksun, T., Goldin-Meadow, S., Newcombe, N., \& Shipley, T. (2013). Individual differences in mental rotation: What does gesture tell us? Cognitive Processing, 14(2), 153-162. https://doi.org/10.1007/s10339013-0549-1

Göksun, T., Lehet, M., Malykhina, K., \& Chatterjee, A. (2013). Naming and gesturing spatial relations: Evidence from focal brain-injured individuals. Neuropsychologia, 51(8), 1518-1527. https://doi.org/10.1016/j neuropsychologia.2013.05.006

Göksun, T., Lehet, M., Malykhina, K., \& Chatterjee, A. (2015). Spontaneous gesture and spatial language: Evidence from focal brain injury. Brain and Language, 150, 1-13. https://doi.org/10.1016/j.bandl.2015.07 .012

Groenewegen, H. J. (2003). The basal ganglia and motor control. Neural Plasticity, 10(1-2), 107-120. https://doi.org/10.1155/NP.2003.107

Harris, I. M., Egan, G. F., Sonkkila, C., Tochon-Danguy, H. J., Paxinos, G., $\&$ Watson, J. D. G. (2000). Selective right parietal lobe activation during mental rotation: A parametric PET study. Brain: A Journal of Neurology, 123(1), 65-73. https://doi.org/10.1093/brain/123.1.65

Haslinger, B., Erhard, P., Kämpfe, N., Boecker, H., Rummeny, E., Schwaiger, M., Conrad, B., \& Ceballos-Baumann, A. O. (2001). Eventrelated functional magnetic resonance imaging in Parkinson's disease before and after levodopa. Brain: A Journal of Neurology, 124(3), 558-570. https://doi.org/10.1093/brain/124.3.558

Helmich, R. C., de Lange, F. P., Bloem, B. R., \& Toni, I. (2007). Cerebral compensation during motor imagery in Parkinson's disease. Neuropsy- 
chologia, 45(10), 2201-2215. https://doi.org/10.1016/j.neuropsychologia.2007.02.024

Herrera, E., \& Cuetos, F. (2012). Action naming in Parkinson's disease patients on/off dopamine. Neuroscience Letters, 513(2), 219-222. https://doi.org/10.1016/j.neulet.2012.02.045

Herrera, E., Cuetos, F., \& Ribacoba, R. (2012). Verbal fluency in Parkinson's disease patients on/off dopamine medication. Neuropsychologia, 50(14), 3636-3640. https://doi.org/10.1016/j.neuropsychologia.2012.09 .016

Herrera, E., Rodríguez-Ferreiro, J., \& Cuetos, F. (2012). The effect of motion content in action naming by Parkinson's disease patients. Cortex, 48(7), 900-904. https://doi.org/10.1016/j.cortex.2010.12.007

Hoehn, M. M., \& Yahr, M. D. (1967). Parkinsonism: Onset, progression, and mortality. Neurology, 17(5), 427-442. https://doi.org/10.1212/WNL 17.5.427

Holler, J., \& Beattie, G. (2002). A micro-analytic investigation of how iconic gestures and speech represent core semantic features in talk. Semiotica, 2002(142), 31-69. https://doi.org/10.1515/semi.2002.077

Hoover, J. E., \& Strick, P. L. (1993). Multiple output channels in the basal ganglia. Science, 259(5096), 819-821. https://doi.org/10.1126/science .7679223

Hostetter, A. (2014). Action attenuates the effect of visibility on gesture rates. Cognitive Science, 38(7), 1468-1481. https://doi.org/10.1111/cogs .12113

Hostetter, A., \& Alibali, M. (2008). Visible embodiment: Gestures as simulated action. Psychonomic Bulletin \& Review, 15(3), 495-514. https://doi.org/10.3758/PBR.15.3.495

Hostetter, A., \& Alibali, M. (2010). Language, gesture, action! A test of the Gesture as Simulated Action framework. Journal of Memory and Language, 63(2), 245-257. https://doi.org/10.1016/j.jml.2010.04.003

Hostetter, A., \& Alibali, M. (2019). Gesture as simulated action: Revisiting the framework. Psychonomic Bulletin and Review, 26(3), 721-752. https://doi.org/10.3758/s13423-018-1548-0

Hsieh, S., Schubert, S., Hoon, C., Mioshi, E., \& Hodges, J. R. (2013). Validation of the Addenbrooke's Cognitive Examination III in frontotemporal dementia and Alzheimer's disease. Dementia and Geriatric Cognitive Disorders, 36(3-4), 242-250. https://doi.org/10.1159/ 000351671

Humphries, S., Holler, J., Crawford, T. J., Herrera, E., \& Poliakoff, E. (2016). A third-person perspective on co-speech action gestures in Parkinson's disease. Cortex, 78, 44-54. https://doi.org/10.1016/j.cortex .2016.02.009

Humphries, S., Klooster, N., Cardillo, E., Weintraub, D., Rick, J., \& Chatterjee, A. (2019). From action to abstraction: The sensorimotor grounding of metaphor in Parkinson's disease. Cortex, 121, 362-384. https://doi.org/10.1016/j.cortex.2019.09.005

Jeannerod, M. (1994). The representing brain: Neural correlates of motor intention and imagery. Behavioral and Brain Sciences, 17(2), 187-202. https://doi.org/10.1017/S0140525X00034026

Jeannerod, M. (2001). Neural simulation of action: A unifying mechanism for motor cognition. NeuroImage, 14(1), S103-S109. https://doi.org/10 .1006/nimg.2001.0832

Jeannerod, M., \& Frak, V. (1999). Mental imaging of motor activity in humans. Current Opinion in Neurobiology, 9(6), 735-739. https://doi .org/10.1016/S0959-4388(99)00038-0

Kemmerer, D. (2015). Are the motor features of verb meanings represented in the precentral motor cortices? Yes, but within the context of a flexible, multilevel architecture for conceptual knowledge. Psychonomic Bulletin \& Review, 22(4), 1068-1075. https://doi.org/10.3758/s13423-0140784-1

Kemmerer, D., Chandrasekaran, B., \& Tranel, D. (2007). A case of impaired verbalization but preserved gesticulation of motion events. Cognitive Neuropsychology, 24(1), 70-114. https://doi.org/10.1080/ 02643290600926667
Kendon, A. (1997). Gesture. Annual Review of Anthropology, 26, 109128. https://doi.org/10.1146/annurev.anthro.26.1.109

Kita, S., Alibali, M. W., \& Chu, M. (2017). How do gestures influence thinking and speaking? The gesture-for-conceptualization hypothesis. Psychological Review, 124(3), 245-266. https://doi.org/10.1037/ rev0000059

Kita, S., \& Özyürek, A. (2003). What does cross-linguistic variation in semantic coordination of speech and gesture reveal?: Evidence for an interface representation of spatial thinking and speaking. Journal of Memory and Language, 48(1), 16-32. https://doi.org/10.1016/S0749596X(02)00505-3

Klooster, N. B., Cook, S. W., Uc, E. Y., \& Duff, M. C. (2015). Gestures make memories, but what kind? Patients with impaired procedura memory display disruptions in gesture production and comprehension. Frontiers in Human Neuroscience, 8, 1054. https://doi.org/10.3389/ fnhum.2014.01054

Kosslyn, S. M., Digirolamo, G. J., Thompson, W. L., \& Alpert, N. M. (1998). Mental rotation of objects versus hands: Neural mechanisms revealed by positron emission tomography. Psychophysiology, 35(2), 151-161. https://doi.org/10.1111/1469-8986.3520151

Kosslyn, S. M., Thompson, W. L., \& Ganis, G. (2006). The case for mental imagery. Oxford University Press. https://doi.org/10.1093/acprof:oso/ 9780195179088.001.0001

Lynott, D., \& Connell, L. (2010). Embodied conceptual combination. Frontiers in Psychology, 1, 212. https://doi.org/10.3389/fpsyg.2010 .00212

Masson-Carro, I., Goudbeek, M., \& Krahmer, E. (2016). Can you handle this? The impact of object affordances on how co-speech gestures are produced. Language, Cognition and Neuroscience, 31(3), 430-440. https://doi.org/10.1080/23273798.2015.1108448

McNeill, D. (1985). So you think gestures are nonverbal? Psychological Review, 92(3), 350-371. https://doi.org/10.1037/0033-295X.92.3.350

McNeill, D. (1992). Hand and mind: What gestures reveal about thought. University of Chicago Press.

McNeill, D. (2012). How language began: Gesture and speech in human evolution. Cambridge University Press. https://doi.org/10.1017/ CBO9781139108669

Mioshi, E., Dawson, K., Mitchell, J., Arnold, R., \& Hodges, J. R. (2006). The Addenbrooke's Cognitive Examination Revised (ACE-R): A brief cognitive test battery for dementia screening. International Journal of Geriatric Psychiatry, 21(11), 1078-1085.

Mizuguchi, N., Nakata, H., \& Kanosue, K. (2016). Motor imagery beyond the motor repertoire: Activity in the primary visual cortex during kinesthetic motor imagery of difficult whole body movements. Neuroscience, 315, 104-113. https://doi.org/10.1016/j.neuroscience.2015.12.013

Neuper, C., Scherer, R., Reiner, M., \& Pfurtscheller, G. (2005). Imagery of motor actions: Differential effects of kinesthetic and visual-motor mode of imagery in single-trial EEG. Cognitive Brain Research, 25(3), 668 677. https://doi.org/10.1016/j.cogbrainres.2005.08.014

Noordzij, M. L., Neggers, S. F. W., Ramsey, N. F., \& Postma, A. (2008). Neural correlates of locative prepositions. Neuropsychologia, 46(5), 1576-1580. https://doi.org/10.1016/j.neuropsychologia.2007.12.022

Ogden, J. A. (1990). Spatial abilities and deficits in aging and age-related disorders. In R. D. Nebes \& S. Corkin (Eds.), Handbook of neuropsychology (Vol. 4, pp. 265-278). Elsevier Science.

Özyürek, A., \& Kita, S. (1999). Expressing manner and path in English and Turkish: Differences in speech, gesture, and conceptualization. Proceedings of the 21st Annual Conference of the Cognitive Science Society (pp. 507-512). Retrieved from https://pure.mpg.de/rest/items/item 68319_6/component/file_532565/content

Özyürek, A., Kita, S., Allen, S., Brown, A., Furman, R., \& Ishizuka, T. (2008). Development of cross-linguistic variation in speech and gesture: Motion events in English and Turkish. Developmental Psychology, 44(4), 1040-1054. https://doi.org/10.1037/0012-1649.44.4.1040 
Özyürek, A., Kita, S., Allen, S., Furman, R., \& Brown, A. (2005). How does linguistic framing of events influence co-speech gestures?: Insights from crosslinguistic variations and similarities. Gesture, 5(1), 219-240.

Parrill, F. (2009). Dual viewpoint gestures. Gesture, 9(3), 271-289. https:// doi.org/10.1075/gest.9.3.01par

Parrill, F. (2010). Viewpoint in speech-gesture integration: Linguistic structure, discourse structure, and event structure. Language and Cognitive Processes, 25(5), 650-668. https://doi.org/10.1080/01690 960903424248

Pasquereau, B., DeLong, M. R., \& Turner, R. S. (2016). Primary motor cortex of the Parkinsonian monkey: Altered encoding of active movement. Brain: A Journal of Neurology, 139(1), 127-143. https://doi.org/ 10.1093/brain/awv312

Péran, P., Cardebat, D., Cherubini, A., Piras, F., Luccichenti, G., Peppe, A., Caltgirone, C., Rasco, O., Démone, J.-F., \& Sabatini, U. (2009). Object naming and action-verb generation in Parkinson's disease: A fMRI study. Cortex, 45(8), 960-971. https://doi.org/10.1016/j.cortex.2009.02 .019

Piatt, A. L., Fields, J. A., Paolo, A. M., Koller, W. C., \& Tröster, A. I. (1999). Lexical, semantic, and action verbal fluency in Parkinson's disease with and without dementia. Journal of Clinical and Experimental Neuropsychology, 21(4), 435-443. https://doi.org/10.1076/jcen.21.4 .435 .885

Pine, K. J., Gurney, D. J., \& Fletcher, B. (2010). The semantic specificity hypothesis: When gestures do not depend upon the presence of a listener. Journal of Nonverbal Behavior, 34(3), 169-178. https://doi.org/10 .1007/s10919-010-0089-7

Podzebenko, K., Egan, G. F., \& Watson, J. D. G. (2002). Widespread dorsal stream activation during a parametric mental rotation task, revealed with functional magnetic resonance imaging. NeuroImage, 15(3), 547-558. https://doi.org/10.1006/nimg.2001.0999

Poliakoff, E. (2013). Representation of action in Parkinson's disease: Imagining, observing, and naming actions. Journal of Neuropsychology, 7(2), 241-254. https://doi.org/10.1111/jnp.12005

Pulvermüller, F. (2005). Brain mechanisms linking language and action. Nature Reviews Neuroscience, 6(7), 576-582. https://doi.org/10.1038/ nrn1706

Pulvermüller, F. (2013). How neurons make meaning: Brain mechanisms for embodied and abstract-symbolic semantics. Trends in Cognitive Sciences, 17(9), 458-470. https://doi.org/10.1016/j.tics.2013.06.004

Pylyshyn, Z. W. (1973). What the mind's eye tells the mind's brain: A critique of mental imagery. Psychological Bulletin, 80(1), 1-24. https:// doi.org/10.1037/h0034650

Ramig, L. O., Sapir, S., Countryman, S., Pawlas, A. A., O'Brien, C., Hoehn, M., \& Thompson, L. L. (2001). Intensive voice treatment $\left(\right.$ LSVT $\left.^{\circledR}\right)$ for patients with Parkinson's disease: A 2 year follow up. Journal of Neurology, Neurosurgery, \& Psychiatry, 71(4), 493-498. https://doi.org/10.1136/jnnp.71.4.493

Rapcsak, S. Z., Ochipa, C., Beeson, P. M., \& Rubens, A. B. (1993). Praxis and the right hemisphere. Brain and Cognition, 23(2), 181-202. https:// doi.org/10.1006/brcg.1993.1054

Rose, M. L. (2006). The utility of arm and hand gestures in the treatment of aphasia. Advances in Speech Language Pathology, 8(2), 92-109. https://doi.org/10.1080/14417040600657948

Sabatini, U., Boulanouar, K., Fabre, N., Martin, F., Carel, C., Colonnese, C., Bozzao, L., Berry, I., Montastruc, J. L., Chollet, F., \& Rascol, O. (2000). Cortical motor reorganization in akinetic patients with Parkinson's disease. Brain: A Journal of Neurology, 123(2), 394-403. https:// doi.org/10.1093/brain/123.2.394

San Miguel Abella, R. A., \& González-Nosti, M. (2020). Motor content norms for 4,565 verbs in Spanish. Behavior Research Methods, 52(2), 447-454. https://doi.org/10.3758/s13428-019-01241-1
Signorini, M., \& Volpato, C. (2006). Action fluency in Parkinson's disease: A follow-up study. Movement Disorders, 21(4), 467-472. https:// doi.org/10.1002/mds.20718

Sloetjes, H., \& Wittenburg, P. (2008). Annotation by category-ELAN and ISO DCR. Proceedings of the 6th International Conference on Language Resources and Evaluation (pp. 816-820). European Language Resources Association. Retrieved from http://www.lrec-conf.org/ proceedings/lrec2008/pdf/208_paper.pdf

Stinear, C. M., Byblow, W. D., Steyvers, M., Levin, O., \& Swinnen, S. P. (2006). Kinesthetic, but not visual, motor imagery modulates corticomotor excitability. Experimental Brain Research, 168(1-2), 157-164. https://doi.org/10.1007/s00221-005-0078-y

Talmy, L. (1985). Lexicalization patterns: Semantic structure in lexical forms. In T. Shopen (Ed.), Language typology and syntactic description: Vol. 3, Grammatical categories and the lexicon (pp. 225-282). Cambridge University Press.

Tomlinson, C. L., Stowe, R., Patel, S., Rick, C., Gray, R., \& Clarke, C. E. (2010). Systematic review of levodopa dose equivalency reporting in Parkinson's disease. Movement Disorders, 25(15), 2649-2653. https:// doi.org/10.1002/mds.23429

Urgesi, C., Berlucchi, G., \& Aglioti, S. M. (2004). Magnetic stimulation of extrastriate body area impairs visual processing of nonfacial body parts. Current Biology, 14(23), 2130-2134. https://doi.org/10.1016/j.cub.2004 .11 .031

van Nuenen, B. F. L., Helmich, R. C., Buenen, N., van de Warrenburg, B. P. C., Bloem, B. R., \& Toni, I. (2012). Compensatory activity in the extrastriate body area of Parkinson's disease patients. The Journal of Neuroscience, 32(28), 9546-9553. https://doi.org/10.1523/JNEUROSCI $.0335-12.2012$

Voisin, J. I. A., Mercier, C., Jackson, P. L., Richards, C. L., \& Malouin, F. (2011). Is somatosensory excitability more affected by the perspective or modality content of motor imagery? Neuroscience Letters, 493(1-2), 33-37. https://doi.org/10.1016/j.neulet.2011.02.015

Willems, R. M., \& Hagoort, P. (2007). Neural evidence for the interplay between language, gesture, and action: A review. Brain and Language, 101(3), 278-289. https://doi.org/10.1016/j.bandl.2007.03.004

Wu, D. H., Morganti, A., \& Chatterjee, A. (2008). Neural substrates of processing path and manner information of a moving event. Neuropsychologia, 46(2), 704-713. https://doi.org/10.1016/j.neuropsychologia .2007.09.016

Wu, T., \& Hallett, M. (2005). A functional MRI study of automatic movements in patients with Parkinson's disease. Brain: A Journal of Neurology, 128(10), 2250-2259. https://doi.org/10.1093/brain/awh569

Wu, T., \& Hallett, M. (2008). Neural correlates of dual task performance in patients with Parkinson's disease. Journal of Neurology, Neurosurgery, \& Psychiatry, 79(7), 760-766. https://doi.org/10.1136/jnnp.2007.126599

Wu, T., Long, X., Wang, L., Hallett, M., Zang, Y., Li, K., \& Chan, P. (2011). Functional connectivity of cortical motor areas in the resting state in Parkinson's disease. Human Brain Mapping, 32(9), 1443-1457. https://doi.org/10.1002/hbm.21118

Yu, H., Sternad, D., Corcos, D. M., \& Vaillancourt, D. E. (2007). Role of hyperactive cerebellum and motor cortex in Parkinson's disease. NeuroImage, 35(1), 222-233. https://doi.org/10.1016/j.neuroimage.2006.11.047

Zadikoff, C., \& Lang, A. E. (2005). Apraxia in movement disorders. Brain: A Journal of Neurology, 128(7), 1480-1497. https://doi.org/10.1093/ brain/awh560

Received October 24, 2019

Revision received September 8, 2020 Accepted September 25, 2020 